\title{
Altered A-Type Potassium Channel Function Impairs Dendritic Spike Initiation and Temporoammonic Long-Term Potentiation in Fragile X Syndrome
}

\author{
Gregory J. Ordemann, Christopher J. Apgar, Raymond A. Chitwood, and ${ }^{\circledR}$ Darrin H. Brager \\ Department of Neuroscience, Institute for Neuroscience, Center for Learning and Memory, University of Texas at Austin, Austin, Texas 78712
}

Fragile X syndrome (FXS) is the leading monogenetic cause of cognitive impairment and autism spectrum disorder. Area CA1 of the hippocampus receives current information about the external world from the entorhinal cortex via the temporoammonic (TA) pathway. Given its role in learning and memory, it is surprising that little is known about TA long-term potentiation (TA-LTP) in FXS. We found that TA-LTP was impaired in male fmrl KO mice. Although there were no significant differences in basal synaptic transmission, synaptically evoked dendritic calcium signals were smaller in KO neurons. Using dendritic recording, we found no difference in complex spikes or pharmacologically isolated $\mathrm{Ca}^{2+}$ spikes; however, the threshold for fast, $\mathrm{Na}^{+}$-dependent dendritic spikes was depolarized in fmr1 $\mathrm{KO}$ mice. Cell-attached patch-clamp recordings found no difference in $\mathrm{Na}^{+}$channels between wild-type and fmrl KO CA1 dendrites. Dendritic spike threshold and TA-LTP were restored by blocking A-type $\mathrm{K}^{+}$channels with either $150 \mu \mathrm{M} \mathrm{Ba}{ }^{2+}$ or the more specific toxin AmmTx3. The impairment of TA-LTP shown here, coupled with previously described enhanced Schaffer collateral LTP, may contribute to spatial memory alterations in FXS. Furthermore, as both of these LTP phenotypes are attributed to changes in A-type $\mathrm{K}^{+}$channels in FXS, our findings provide a potential therapeutic target to treat cognitive impairments in FXS.

Key words: CA1; calcium; dendrite; FMRP; LTP

\section{Significance Statement}

Alterations in synaptic function and plasticity are likely contributors to learning and memory impairments in many neurologic disorders. Fragile $\mathrm{X}$ syndrome is marked by dysfunctional learning and memory and changes in synaptic structure and function. This study shows a lack of LTP at temporoammonic synapses in CA1 neurons associated with biophysical differences in A-type $\mathrm{K}^{+}$channels in fmr1 KO CA1 neurons. Our results, along with previous findings on A-type $\mathrm{K}^{+}$channel effects on Schaffer collateral LTP, reveal differential effects of a single ion channelopathy on LTP at the two major excitatory pathways of CA1 pyramidal neurons. These findings expand our understanding of memory deficits in FXS and provide a potential therapeutic target for the treatment of memory dysfunction in FXS.

\section{Introduction}

Fragile X syndrome (FXS), caused by transcriptional silencing of the fmrl gene and loss of the Fragile $\mathrm{X}$ mental retardation

\footnotetext{
Received Jan. 13, 2021; revised Apr. 19, 2021; accepted Apr. 26, 2021

Author contributions: G.J.O. and D.H.B. designed research; G.J.O., C.J.A., R.A.C., and D.H.B. performed research; G.J.O., C.J.A., R.A.C., and D.H.B. analyzed data; and G.J.O. and D.H.B. wrote the paper.

This work was supported by National Institutes of Health Grant R01 MH100510 (D.H.B.), the Franklyn Alexander Endowed Fellowship (G.J.0.), and an Institutional Training Grant 5T32DA018926 from the National Institutes of Health. We thank Dr. Richard Gray for assistance with analysis programs, Meagan Volquardsen for genotyping and mouse colony management, and members of the Johnston Lab for comments on this manuscript.

R.A. Chitwood's present address: Department of Neuroscience, Baylor College of Medicine, Houston, Texas 77030 .

The authors declare no competing financial interests.

Correspondence should be addressed to Darrin H. Brager at dbrager@mail.clm.utexas.edu.

https://doi.org/10.1523/JNEUROSCI.0082-21.2021

Copyright $(2021$ the authors
}

protein (FMRP; Martin and Bell, 1943; Lubs, 1969; Verkerk et al., 1991; Tassone et al., 2000), is the leading monogenetic cause of autism and intellectual disability, affecting $\sim 1$ in 4000 males and 1 in 6000 females (Martin and Bell, 1943; Brown et al., 1982; Kemper et al., 1988; Turner et al., 1996; Rogers et al., 2001). FMRP controls many neuronal proteins, including those involved in synaptic structure, function, and plasticity, through translational regulation of target mRNAs (Bassell and Warren, 2008; Darnell et al., 2011) and direct protein-protein interactions (Ramos et al., 2006; Brown et al., 2010; Deng et al., 2013, 2019; Brandalise et al., 2020). Given its high level of FMRP expression, well-defined circuitry, and relevance to learning and memory processes, the hippocampus has been critical to understanding synaptic changes in FXS (Scoville and Milner, 1957; Squire, 1992; Ludwig et al., 2014). The Schaffer collateral CA3 to CA1 synapse has been extensively studied in FXS (Huber et al., 2002; Shang et al., 2009; Brager et al., 2012; Routh et al., 2013; Bostrom et al., 
2015; Toft et al., 2016; Wang et al., 2016). By contrast, few studies have investigated the temporoammonic (TA) entorhinal cortex to CA1 synapses. Wahlstrom-Helgren and Klyachko, 2015 found no difference in TA synaptic transmission using somatic whole-cell recording; whereas Booker et al. (2020), found that TA synaptic transmission was reduced in $f m r 1$ knock-out (KO) mice using extracellular field potential recording. Neither of these studies, however, investigated TA long-term potentiation (LTP). Given the lack of LTP studies and the critical involvement of the TA pathway in the consolidation of long-term memory (Remondes and Schuman, 2004) and its necessity for the generation of hippocampal CA1 place fields (Bittner et al., 2017), we asked whether TA-LTP is altered in FXS.

CA1 pyramidal neuron dendrites express $\mathrm{Na}^{+}, \mathrm{K}^{+}, \mathrm{Ca}^{2+}$, and h-channels, which play crucial roles in dendritic integration and the induction of LTP. We previously showed that the functional expression of dendritic h-channels $\left(\mathrm{I}_{\mathrm{h}}\right)$ is higher in $f m r 1$ KO CA1 neurons (Brager et al., 2012; Brandalise et al., 2020). We also demonstrated that the current carried by dendritic Atype $\mathrm{K}^{+}$channels $\left(\mathrm{I}_{\mathrm{KA}}\right)$ is reduced in $f m r 1 \mathrm{KO}$ CA1 neurons (Routh et al., 2013). These changes alter the local integrative properties and increase the backpropagation of action potentials, respectively. Although the effect of these changes in dendritic hchannels and $\mathrm{I}_{\mathrm{KA}}$ on Schaffer collateral LTP were previously described (Brager et al., 2012; Routh et al., 2013), the impact on TA-LTP remains unknown.

Using somatic and dendritic recording, we found that TALTP following theta-burst stimulation was impaired in fmrl KO mice. The lack of LTP was not because of the higher expression of h-channels as a block of $\mathrm{I}_{\mathrm{h}}$ with ZD7288 did not rescue LTP. Two photon imaging during bursts of TA stimulation revealed that dendritic $\mathrm{Ca}^{2+}$ signals were smaller in fmr1 KO neurons. Although complex and pharmacologically isolated $\mathrm{Ca}^{2+}$ spikes recorded in the dendrites were not different, the threshold for fast dendritic spikes (dspikes) was more depolarized in fmr1 KO CA1 pyramidal neurons. Application of extracellular $\mathrm{Ba}^{2+}$ or AmmTx3 to block $\mathrm{I}_{\mathrm{KA}}$ rescued dspike threshold and TA-LTP in fmr1 KO CA1 pyramidal neurons, implicating A-type $\mathrm{K}^{+}$ channels.

\section{Materials and Methods}

Animals. The University of Texas at Austin Institutional Animal Care and Use Committee approved all animal procedures. Male wildtype and $\mathrm{fmr} 1 \mathrm{KO}$ C57/B6 mice from 8 to 16 weeks old were used for all experiments. fmr1 $\mathrm{KO}$ male and homozygous female fmr1 $\mathrm{KO}$ mice were paired to produce litters of $f m r 1 \mathrm{KO}$ animals. Mice were weaned at postnatal day 20. Animals were housed in single-sex groups at room temperature with ad libitum access to food and water and set on a reverse $12 \mathrm{~h}$ light cycle in the University of Texas at Austin vivarium located in the Norman Hackerman Building.

Preparation of acute brain slices. Mice were anesthetized with acute isofluorane exposure followed by injection of a ketamine/xylazine cocktail (100/10 mg/kg i.p.). Mice were then perfused through the heart with ice-cold saline consisting of the following (in $\mathrm{mM}$ ): $2.5 \mathrm{KCl}, 1.25$ $\mathrm{NaH}_{2} \mathrm{PO}_{4}, 25 \mathrm{NaHCO}_{3}, 0.5 \mathrm{CaCl}_{2}, 7 \mathrm{MgCl}_{2}, 7$ dextrose, 205 sucrose, 1.3 ascorbate, and $3 \mathrm{Na}^{+}$pyruvate (bubbled with $95 \% \mathrm{O}_{2} / 5 \% \mathrm{CO}_{2}$ to maintain $\mathrm{pH}$ at $\sim 7.4$ ). The brain was removed, trimmed, and sectioned into $300-\mu \mathrm{m}$-thick transverse slices of the middle hippocampus using a vibrating tissue slicer (Vibratome 3000, Vibratome; Brager et al., 2012; Brandalise et al., 2020). Slices were held for $30 \mathrm{~min}$ at $35^{\circ} \mathrm{C}$ in a chamber filled with artificial cerebral spinal fluid (aCSF) consisting of the following (in mM): $125 \mathrm{NaCl}, 2.5 \mathrm{KCl}, 1.25 \mathrm{NaH}_{2} \mathrm{PO}_{4}, 25 \mathrm{NaHCO}_{3}, 2 \mathrm{CaCl}_{2}, 2$ $\mathrm{MgCl}_{2}, 10$ dextrose, and $3 \mathrm{Na}^{+}$pyruvate (bubbled with 95\% $\mathrm{O}_{2} / 5 \%$ $\mathrm{CO}_{2}$ ) and then held at room temperature until the time of recording.
Electrophysiology. Slices were submerged in a heated $\left(32-34^{\circ} \mathrm{C}\right) \mathrm{re}-$ cording chamber and continually perfused $(1-2 \mathrm{ml} / \mathrm{min})$ with bubbled aCSF containing the following (in $\mathrm{mm}$ ): $125 \mathrm{NaCl}, 3.0 \mathrm{KCl}, 1.25$ $\mathrm{NaH}_{2} \mathrm{PO}_{4}, 25 \mathrm{NaHCO}_{3}, 2 \mathrm{CaCl}_{2}, 1 \mathrm{MgCl}_{2}, 10$ dextrose, $3 \mathrm{Na}^{+}$pyruvate, 0.005 CGP 55845, and 0.002 gabazine. To reduce recurrent excitation, a cut was made between area CA3 and area CA1. CA1 pyramidal neuron dendrites or somata were visually identified using differential interference contrast or Dodt contrast optics.

Whole-cell current-clamp recordings. Patch pipettes (4-8 M $\Omega$ somatic, 7-11 $\mathrm{M} \Omega$ dendritic) were pulled from borosilicate glass and filled with the following (in $\mathrm{mm}$ ): $120 \mathrm{~K}$-Gluconate, $16 \mathrm{KCl}, 10$ HEPES, 8 $\mathrm{NaCl}, 7 \mathrm{~K}_{2}$ phosphocreatine, $0.3 \mathrm{Na}-\mathrm{GTP}, 4 \mathrm{Mg}-\mathrm{ATP}$ (pH 7.3, with $\mathrm{KOH}$ ). Neurobiotin (2\%; Vector Laboratories) was included in the internal recording solution to determine the recording location during post hoc morphologic reconstruction. Neurons that had a significant portion of the oblique or apical dendrites cut were excluded from analysis. In some cases, Alexa Fluor 594 was used to provide real time feedback of dendritic morphology.

Data were acquired using a Dagan BVC-700A amplifier and AxoGraph $\mathrm{X}$ or custom data acquisition software written using Igor Pro (WaveMetrics). Data were sampled at $10-50 \mathrm{kHz}$, filtered at $3-5 \mathrm{kHz}$, and digitized using an ITC-18 interface (InstruTECH). Pipette capacitance and series resistance were monitored and adjusted throughout each recording. Series resistance was monitored throughout each experiment, and the experiment was discarded if series resistance exceeded 30 $\mathrm{M} \Omega(50 \mathrm{M} \Omega$ for dendritic recordings). Experiments in which the resting membrane potential was more depolarized than $-50 \mathrm{mV}$ were discarded. The liquid junction potential was estimated to be $14.3 \mathrm{mV}$ (Patcher's Power Tools Igor Pro) and was not corrected.

Extracellular stimulation was performed using bipolar sharp tungsten electrodes ( $5 \mathrm{M} \Omega, 8^{\circ}$ taper; A-M Systems) connected to an NL800A current stimulus isolator (Digitimer). The temporoammonic inputs were targeted by visually locating the axon fibers in the stratum lacunosum moleculare (SLM) region ( $\geq 250 \mu \mathrm{m}$ from CA1 stratum pyramidale) and lowering the tungsten electrode until the tip was $\sim 10 \mu \mathrm{m}$ below the surface of the tissue. Stimulation intensity was increased until reliable EPSP (1-2 $\mathrm{mV}$ for somatic recordings and $2-4 \mathrm{mV}$ for dendritic recordings) was elicited. To isolate NMDAR-dependent EPSPs (see Fig. 4) $\mathrm{MgCl}_{2}$ was removed from the extracellular aCSF and $20 \mu \mathrm{M}$ DNQX added to block AMPA receptors.

Induction of long-term potentiation. Long-term potentiation was performed using theta burst stimulation (TBS) as previously described (Tsay et al., 2007). Baseline EPSPs were stimulated at $0.067 \mathrm{~Hz}$ for $5 \mathrm{~min}$. LTP was induced using TBS with bursts of 10 stimuli at $100 \mathrm{~Hz}$, performed in five trains at $5 \mathrm{~Hz}$, and each set of TBS was repeated four times at $20 \mathrm{~s}$ intervals. EPSPs were then recorded for $\sim 30 \mathrm{~min}$ post TBS. The change in EPSP slope was plotted normalized to the baseline period.

Analysis of current-clamp data. Data were analyzed using AxoGraph $\mathrm{X}$ or custom analysis software written in Igor Pro. EPSP summation was quantified as the ratio of the amplitude of the fifth EPSP to the amplitude of the first EPSP. Paired-pulse ratio was calculated as the slope of the second EPSP divided by the slope of the first EPSP. Input-output was measured by increasing the magnitude of stimulus and measuring the slope of the resulting EPSP. For a given input-output experiment (see Figs. 1, 4, 5) the same stimulation electrode was used throughout to reduce variability within the experiment (But note that stimulation amplitudes differed across the experiments.).

Complex spikes were elicited by delivering square current injections (50-450 pA for $1 \mathrm{~s})$. The width of a complex spike was calculated differentially depending on the number of $\mathrm{Ca}^{2+}$-dependent events following the initial fast spike. For one slow spike, the width was calculated as the half-width from the initiation point of the spike to the peak of the event. When two or three $\mathrm{Ca}^{2+}$-dependent spikes occurred, the width was calculated using methods for the measurement of dendritic $\mathrm{Ca}^{2+}$ plateau width modified from Takahashi and Magee (2009). For these events, width was taken as the halfway point between the initiation point of the first slow event and the lowest trough between events (see Fig. 6B).

Dendritic $\mathrm{Ca}^{2+}$ spikes were isolated with the addition of $0.5 \mu \mathrm{M}$ TTX and $50 \mu \mathrm{M} 4$-AP. Spikes were generated by injecting square current 

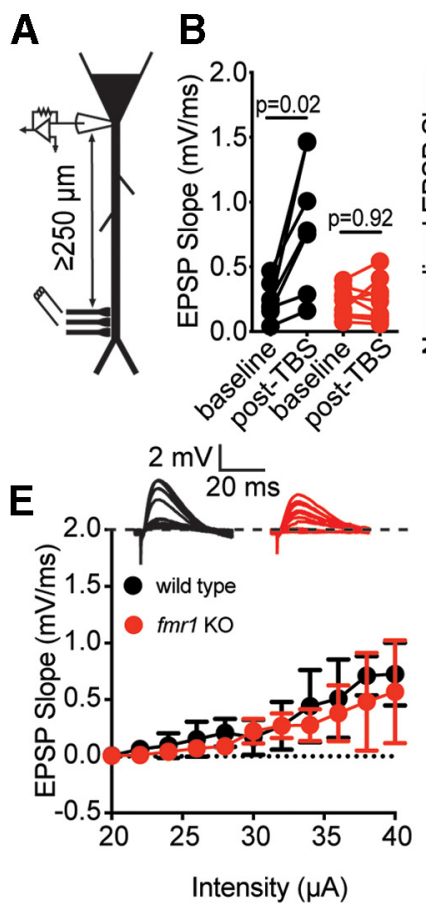
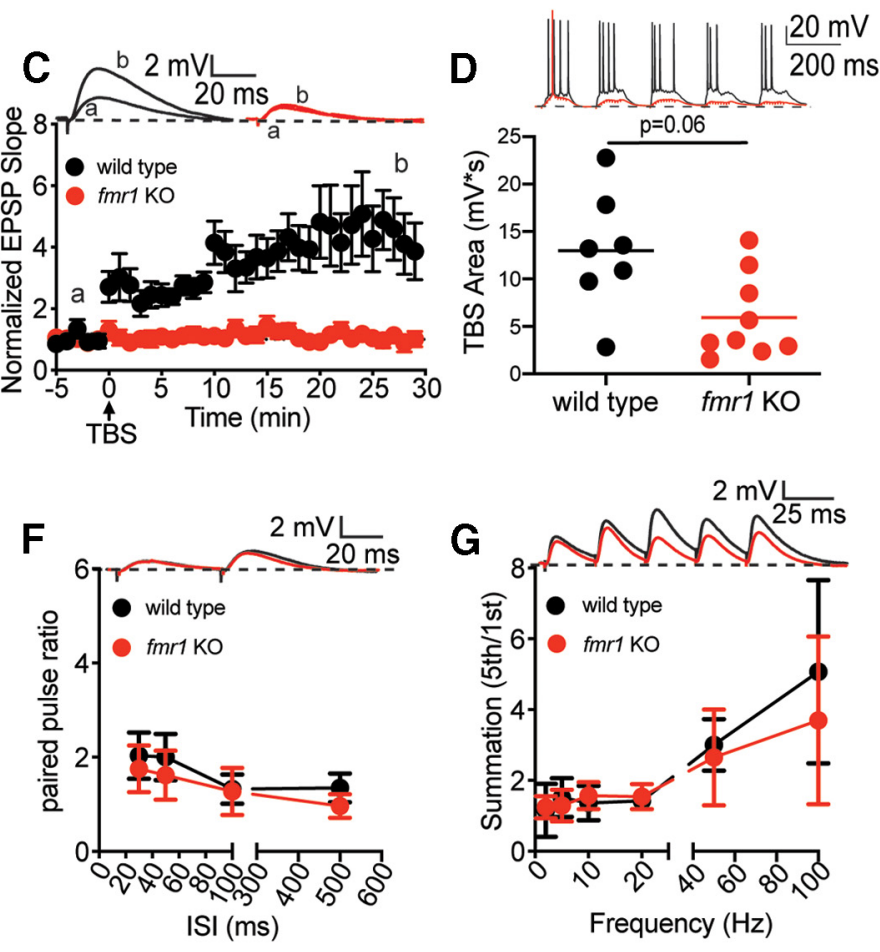

Figure 1. TA-LTP is impaired in fmr $1 \mathrm{KO}$ CA1 pyramidal neurons. $\boldsymbol{A}$, Diagram of recording configuration for somatic EPSP measurements. $\boldsymbol{B}$, EPSP slope is increased 30 min after TBS in wildtype but not fmr $1 \mathrm{KO}$ CA1 neurons; baseline (mean of 5 min before TBS), post-TBS (mean of 5 min at the end of recording; wild type: Wilcoxon, $W=28, p=0.02, \eta^{2}=0.79$; fmr $1 \mathrm{KO}$ : baseline, $0.23 \pm 0.04$. post-TBS, $0.24 \pm 0.05 \mathrm{mV} / \mathrm{ms}$, Wilcoxon, $W=-3, p=0.92$ ). C, Normalized change in EPSP slope for wild-type and fmr $1 \mathrm{KO}$ CA1 neurons. Inset, Representative EPSP traces from baseline (a) and post-TBS (b). $\boldsymbol{D}$, Graph of area under the curve during TBS (Mann-Whitney, $U=13, p=0.06$ ) $\boldsymbol{E}$, Input output of TA inputs measuring EPSP slope (two-way RM ANOVA, $\left.F_{(1,7)}=0.65, p=0.45\right)$. Inset, representative experiments from wild-type and fmr $1 \mathrm{KO}$ neurons. $\boldsymbol{F}$, Paired pulse ratio as a function of interstimulus interval (ISI; two-way RM ANOVA, $F_{(1,9)}=$ $4.23, p=0.07)$. Inset, Representative $50 \mathrm{~ms}$ ISI traces. $\mathbf{G}$, Temporal summation of TA EPSPs as a function of frequency (two-way RM ANOVA, $\left.F_{(1,9)}=0.55, p=0.48\right)$. Inset, Representative $50 \mathrm{~Hz}$ traces.

pulses $1000 \mathrm{~ms}$ long and varying between 50 and $700 \mathrm{pA}$ with $50 \mathrm{pA}$ intervals. Because $\mathrm{Ca}^{2}$-dependent spikes have a much slower time course compared with $\mathrm{Na}^{+}$-dependent spikes, measurements that used the second derivative of the voltage response (Gasparini et al., 2004) are not reliable. The threshold of somatically recorded action potentials occurs at $\sim 8 \%$ of the maximum $\mathrm{dV} / \mathrm{dt}$. We therefore estimated the $\mathrm{Ca}^{2+}$ spike threshold using the time when $\mathrm{dV} / \mathrm{dt}$ was $8 \%$ of maximum. Amplitude was measured as the difference from baseline membrane potential to the peak of the first $\mathrm{Ca}^{2+}$ spike.

Dendritic $\mathrm{Na}^{+}$spike experiments were performed on dendritic recordings between 200 and $300 \mu \mathrm{m}$ from the soma. Spikes were generated by injecting a series of double exponential currents $\left(\tau_{1}=0.1 \mathrm{~ms}\right.$ $\tau_{2}=2 \mathrm{~ms}$ ) ranging in amplitude between $500 \mathrm{pA}$ and $5000 \mathrm{pA}$ at 100 or $500 \mathrm{pA}$ intervals. The threshold for dspikes was calculated as $20 \%$ of the second peak of the second derivative of the voltage response (Gasparini et al., 2004).

Input resistance $\left(\mathrm{R}_{\mathrm{N}}\right)$ was calculated from the linear portion of the current-voltage relationship generated in response to a family of current injections ( -50 to $+50 \mathrm{pA}, 10 \mathrm{pA}$ steps).

2-Photon $\mathrm{Ca}^{2+}$ imaging. $\mathrm{Ca}^{2+}$ imaging experiments were performed on a Prairie Ultima Two-Photon Imaging system (Bruker) arranged for in vitro patch-clamp recording. An ultra-fast, pulsed laser beam (Mai Tai, Spectra-Physics) was used at $920 \mathrm{~nm}$ for imaging. Recording pipettes were filled with Oregon Green BAPTA-1 (OGB-1; $100 \mu$; Invitrogen) and Alexa Fluor 594 (40 $\mu \mathrm{m}$; Invitrogen). Line scans across the distal dendrites were performed at $500 \mathrm{~Hz}$ with a dwell time of $4 \mu \mathrm{s}$ for between 400 and $1200 \mathrm{~ms}$. Imaging location was chosen $\sim 50 \mu \mathrm{m}$ more proximal to the soma in reference to the extracellular stimulating electrode.

Analysis of line scans were performed using ImageJ (National Institutes of Health) by placing a line through the fluorescent signal and plotting the profile before converting to a number array (Schneider et al., 2012). Changes in $\mathrm{Ca}^{2+}$ were quantified using $\Delta \mathrm{F} / \mathrm{F}$, where $\mathrm{F}$ is the baseline fluorescence before stimulation and $\Delta \mathrm{F}$ is the change in fluorescence during neuronal stimulation. $\mathrm{Ca}^{2+}$ signal traces were smoothed using a Savitsky-Golay function (Igor Pro, WaveMetrics).

Voltage-clamp recordings of $\mathrm{Na}^{+}$current. Cell attached voltageclamp recordings were performed using an AxoPatch 200B Amplifier (Molecular Devices). Data were acquired at $50 \mathrm{kHz}$ and filtered at $2 \mathrm{kHz}$ and then digitized using an ITC-18 interface (InstruTECH) and recorded using custom Igor Pro software (Igor Pro version 7, WaveMetrics). Pipette solution for cell attached $\mathrm{Na}^{+}$channel recordings consisted of the following (in $\mathrm{mM}$ ): $140 \mathrm{NaCl}, 2.5 \mathrm{KCl}, 2 \mathrm{CaCl}_{2}, 1 \mathrm{MgCl}_{2}$, 10 HEPES, 10 TEA, 1 3,4-Diaminopyridine, 14 -AP. $\mathrm{Na}^{+}$currents were elicited using depolarizing voltage commands from -70 to $20 \mathrm{mV}$ in $10 \mathrm{mV}$ steps from a holding potential of $-90 \mathrm{mV}$. Steady-state inactivation was measured using depolarizing test pulses to a fixed potential $(0 \mathrm{mV})$ preceded by a series of prepulse conditioning potentials ranging from -100 to $-20 \mathrm{mV}$ in $10 \mathrm{mV}$ increments. Linear leakage and capacitive currents were digitally subtracted by scaling traces at smaller voltages in which no voltage dependent current was activated. Activation data were plotted as normalized conductance and steady-state inactivation as normalized current. Activation and inactivation data were fit to a single Boltzmann function using a least squares program.

NEURON modeling. We used a previously validated model (Gasparini et al., 2004) on dspike initiation to test the effects of A-type $\mathrm{K}^{+}$channel alteration on dspike threshold. Modeling was performed using the NEURON environment (https://neuron.yale.edu/neuron/; Carnevale and Hines, 2009). The model used in this study was obtained from ModelDB (accession \#44050; McDougal et al., 2017). Minor alterations were made to the model parameters to better reflect experimental procedures in the present study. A single, double exponential stimulus injection $\left(\tau_{1}=0.1 \mathrm{~ms} \tau_{2}=2 \mathrm{~ms}\right)$ was delivered to the apical dendrite of a model neuron, and the stimulus amplitude increased until a dspike was generated. Dspike data were exported to Igor Pro (WaveMetrics) and analyzed as described above for current-clamp recordings. Under 
normal wild-type conditions, A-type $\mathrm{K}^{+}$channel $\mathrm{V}_{1 / 2}$ is $-0.1 \mathrm{mV}$, and the conductance density $\left(\mathrm{G}_{\text {density }}\right)$ is $0.008 \mathrm{pS} / \mathrm{cm}^{2}$. To mimic the known phenotype of A-type $\mathrm{K}^{+}$channels in fmr1 KO CA1 pyramidal neurons (Routh et al., 2013), $\mathrm{V}_{1 / 2}$ was hyperpolarized to $-10.9 \mathrm{mV}$ and $\mathrm{G}_{\text {density }}$ decreased to $0.0035 \mathrm{pS} / \mathrm{cm}^{2}$. No other neuron properties were altered to isolate the effects of altered A-type $\mathrm{K}^{+}$channel properties on dspikes.

$D A B$ reaction and cellular reconstruction. Slices with cells filled with Neurobiotin (Vector Laboratories) during current-clamp experiments were fixed in $3 \%$ glutaraldehyde for a minimum of $24 \mathrm{~h}$. Slices were washed in $0.1 \mathrm{M}$ phosphate buffer (PB) and incubated in $0.5 \% \mathrm{H}_{2} \mathrm{O}_{2}$ for $30 \mathrm{~min}$. Slices were then washed in $\mathrm{PB}$ and incubated in $\mathrm{ABC}$ reagent (Vector Laboratories) containing Avidin $\mathrm{DH}$ and biotinylated horseradish peroxidase $\mathrm{H}$ for $24-48 \mathrm{~h}$ at $4^{\circ} \mathrm{C}$. Slices were then incubated in DAB solution (Vector Laboratories) in the presence of $\mathrm{H}_{2} \mathrm{O}_{2}$ and monitored for a visible color change to the slices and Neurobiotin-filled cell. Slices were dehydrated in glycerol and mounted on glass slides for imaging. Identifiable neurons were reconstructed at $40 \times$ magnification using a Leitz Diaplan microscope with Neurolucida version 6.0 software (MBF Bioscience). The Sholl radius was set so there were 10 and 25 concentric circles measuring the basal dendrites and apical dendrites, respectively.

Experimental design and statistical analysis. The use of male wildtype and fmrl $\mathrm{KO}$ mice was interleaved during each set of experiments. Where possible, experimenters were blind to the condition of the animal during experimentation and analysis. Experiments were designed as a comparison between wild-type and $f m r 1 \mathrm{KO}$ mice.

Either the Mann-Whitney rank sum test or Wilcoxon matched pairs (for paired, non-normal data) were used to avoid errors arising from non-normal data distributions. Two-way repeated measures (RM) ANOVA was applied to experiments with multiple test variables for each genotype. Sidak's multiple comparison test was used to compare row means between groups. Data are presented as mean \pm SE. Alpha was set to 0.05 for all experiments. Effect size, a measure of the amount of variance accounted for by differences between groups, is reported as $\eta^{2}$ only when $p<0.05 ; \eta^{2}$ effect sizes are defined as small, 0.01 ; medium, 0.06; and large, 0.14. (Cohen, 1988). Statistics were calculated using Prism software (GraphPad).

\section{Results}

\section{Long-term potentiation of TA synapses is impaired in fmrl KO mice}

We made somatic whole-cell current-clamp recordings from CA1 pyramidal neurons in wild-type and fmrl $\mathrm{KO}$ male mice and recorded TA EPSPs before and after TBS to induce TA-LTP (Tsay et al., 2007; Fig. 1A). In wild-type neurons, TA EPSP slope increased $30 \mathrm{~min}$ post-TBS (Fig. $1 B, C$; wild type: $n=7$ from 6 mice; pre-TBS: $0.24 \pm 0.054 \mathrm{mV} / \mathrm{ms}$; post-TBS: $0.84 \pm 0.19 \mathrm{mV} /$ ms. Wilcoxon, $W=28, p=0.02, \eta^{2}=0.79$.). By contrast, in $f m r 1$ KO CA1 neurons TA EPSP slope was not increased after TBS (Fig. $1 B, C$; fmrl KO: $n=9$ from 7 mice; pre-TBS: $0.23 \pm$ $0.04 \mathrm{mV} / \mathrm{ms}$, post-TBS: $0.24 \pm 0.05 \mathrm{mV} / \mathrm{ms}$. Wilcoxon, $W=-3$, $p=0.92$ ). The somatic depolarization during the TBS (area under the curve) was not different between wild-type and fmr1 KO CA1 pyramidal neurons (Fig. 1D; wild type: $12.97 \pm 2.38 \mathrm{mV}^{\star} \mathrm{ms}$; fmr $1 \mathrm{KO}: 5.93 \pm 1.48 \mathrm{mV}^{\star} \mathrm{ms}$; MannWhitney, $U=13, p=0.06$ ). In agreement with previous work (Wahlstrom-Helgren and Klyachko, 2015), we found no difference in postsynaptic responsiveness to single TA stimuli (Fig. $1 E$; wild type: $n=5$ from 4 mice; fmr 1 KO: $n=6$ from 4 mice; two-way RM ANOVA, $\left.F_{(1,7)}=0.65, p=0.45\right)$, baseline paired-pulse ratio (Fig. $1 F$; wild type: $n=5$ from 4 mice; $f m r 1$ KO: $n=6$ from 4 mice; two-way RM ANOVA: $\mathrm{F}_{(1,9)}=4.23$, $p=0.07$ ) or temporal summation (Fig. $1 G$; wild type: $n=5$ from 4 mice; fmr1 KO: $n=6$ from 4 mice; two-way RM ANOVA, $\left.F_{(1,9)}=0.55, p=0.48\right)$ between wild-type and $f m r 1$ $\mathrm{KO}$ neurons. Paired-pulse ratio was also not changed post-

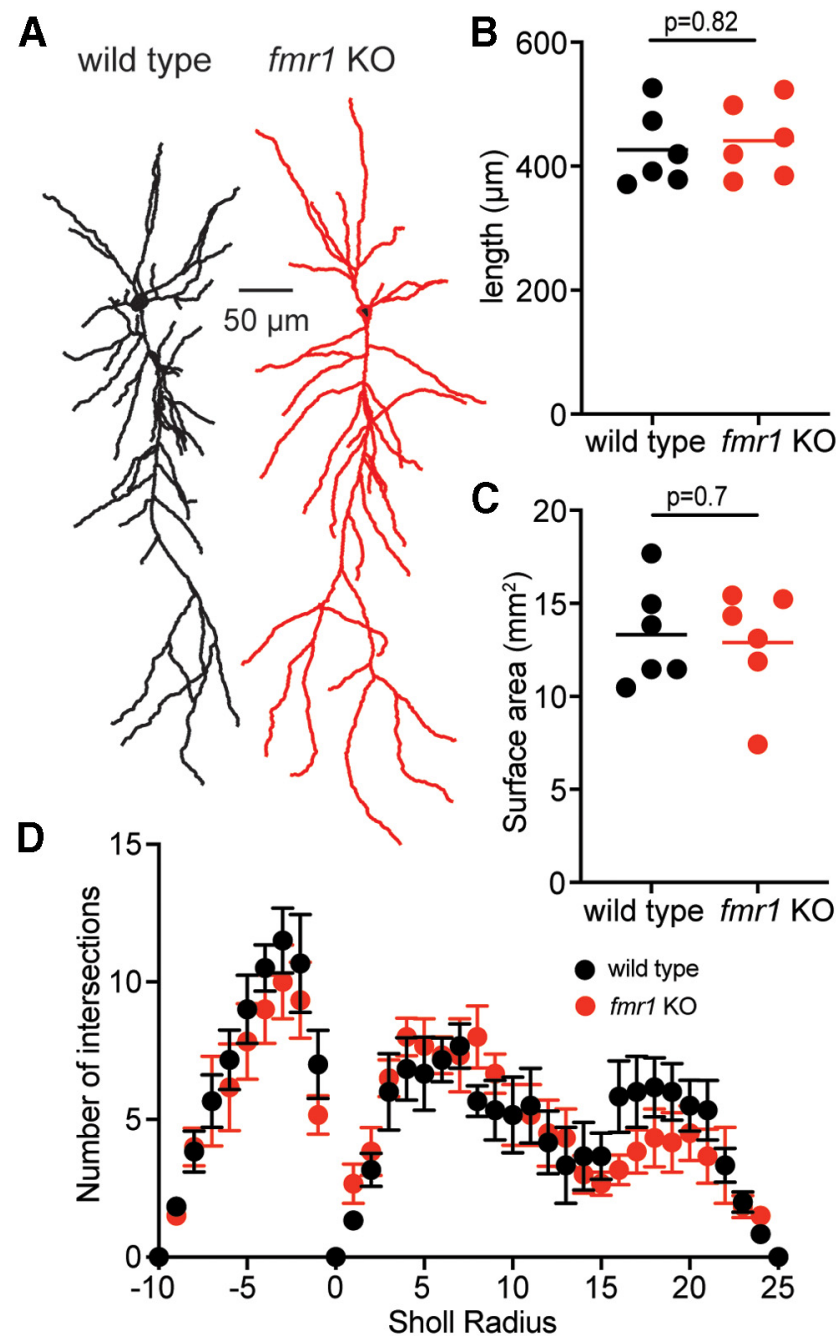

Figure 2. CA1 pyramidal neuron morphology is not different between wild-type and fmr1 KO mice. $A$, Representative neuronal reconstructions of wild-type (black) and fmr $1 \mathrm{KO}$ (red) CA1 pyramdial neurons. $\boldsymbol{B}, \boldsymbol{C}$, Total dendritic length $(\boldsymbol{B} ;$ Mann-Whitney, $U=16, p=0.82)$ and surface area $(\boldsymbol{C}$; Mann-Whitney, $U=15, p=0.7)$ are not different between wild-type and fmr 1 KO CA1 neurons. D, Dendritic branching is not different between wild-type and fmr1 K0 CA1 pyramidal neurons (two-way RM ANOVA, $F_{(1,10)}=0.19, p=0.67$ ).

TBS consistent with a postsynaptic locus of LTP (wild type: two-way RM ANOVA, $F_{(1,4)}=3.53, p=0.13$; fmr1 KO: twoway RM ANOVA, $\left.F_{(1,5)}=3.98, p=0.1\right)$.

\section{Dendritic morphology is not different in wild-type and $\mathrm{fmr} 1$ KO CA1 pyramidal neurons}

We filled CA1 pyramidal neurons with neurobiotin during whole-cell recording for post hoc morphologic reconstruction and analysis (Fig. 2A). There was no significant difference in the neuronal surface area (Fig. $2 B$; wild type: $n=6$ from 4 mice; $13.3 \pm 1.1 \mathrm{~mm}^{2}$; fmr $1 \mathrm{KO}: n=6$ from 4 mice; $12.9 \pm 1.2 \mathrm{~mm}^{2}$; Mann-Whitney, $U=16, p=0.82$ ) or somato-dendritic length, measured as straight line distance from the soma to the tip of the most distal dendrite, (Fig. $2 C$; wild type: $426.6 \pm 25.01 \mu \mathrm{m}$; fmr 1 KO: $441.3 \pm 24.56 \mu \mathrm{m}$; Mann-Whitney, $U=15, p=0.7)$ between wild-type and fmr1 KO CA1 pyramidal neurons. We used Sholl analysis to compare dendritic branching between wild-type and fmr1 KO neurons. There was no difference in dendritic morphology between wild-type and fmr1 KO CA1 pyramidal neurons (Fig. $2 D$; two-way RM ANOVA, $F_{(1,10)}=0.19, p=0.67$ ). 

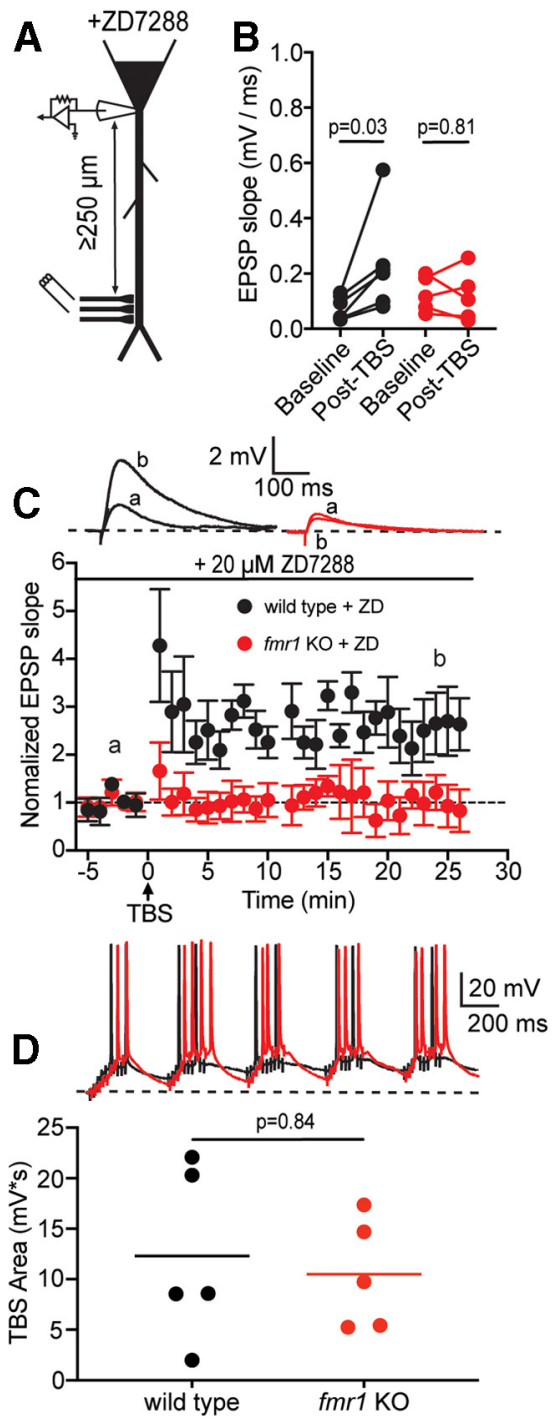

Figure 3. Block of h-channels by $20 \mu \mathrm{m}$ ZD7288 does not rescue TA-LTP in fmr 1 KO CA1 pyramdial neurons. $\boldsymbol{A}$, Recording paradigm during TA-LTP experiments. $\boldsymbol{B}$, EPSP slope is significantly increased $30 \mathrm{~min}$ after TBS in wild-type but not $f m r 1 \mathrm{KO}$ CA1 neurons (wild type: Wilcoxon, $W=21, p=0.03, \eta^{2}=0.811$; fmr1 K0: Wilcoxon, $W=-3, p=0.81$. $C$, Normalized EPSP slope $5 \mathrm{~min}$ before and $30 \mathrm{~min}$ after TBS of TA inputs. Inset, Representative baseline and post-TBS EPSPs from wild-type and fmr 1 KO CA1 neurons. $D$, Graph of the area under the curve during TBS in the presence of ZD7288 (Mann-Whitney, $U=11, p=0.84$ ).

Together, these data show that although TA-LTP is impaired in fmr1 KO CA1 neurons, basal TA synaptic transmission and CA1 neuron morphology are normal.

Block of $\mathrm{I}_{\mathrm{h}}$ does not rescue TA-LTP in $f m r 1 \mathrm{KO}$ neurons The expression of h-channels in the distal dendrites of CA1 pyramidal neurons constrains TA inputs and LTP (Tsay et al., 2007). We previously showed that dendritic $\mathrm{I}_{\mathrm{h}}$ is elevated in $\mathrm{fmr} 1$ KO CA1 pyramidal neurons compared with wild type (Brager et al., 2012; Brandalise et al., 2020). Higher $\mathrm{I}_{\mathrm{h}}$ in $f m r 1$ KO CA1 neurons may reduce the effectiveness of TA synapses in the distal dendrites and impair LTP (Magee, 1998, 1999). To test this hypothesis, we repeated the TBS TA-LTP experiments with $\mathrm{I}_{\mathrm{h}}$ blocked by $20 \mu \mathrm{M}$ ZD7288 (Fig. 3A). With $\mathrm{I}_{\mathrm{h}}$ blocked, TBS significantly potentiated TA EPSPs in wild-type $(n=6$ from 4 mice; pre-TBS: $0.076 \pm 0.018 \mathrm{mV} / \mathrm{ms}$, post-TBS: $0.23 \pm 0.073 \mathrm{mV} / \mathrm{ms}$. Wilcoxon, $W=21, p=0.03, \eta^{2}=0.81$ ) but not fmr1 KO CA1 pyramidal neurons (Fig. $3 B, C ; n=5$ from 4 mice; pre-TBS: $0.13 \pm 0.029 \mathrm{mV} / \mathrm{ms}$, post-TBS: $0.12 \pm 0.041 \mathrm{mV} / \mathrm{ms}$. Wilcoxon, $W=-3, p=0.81$ ). Our results showed no difference in the area under the curve during TBS of TA inputs in the presence of ZD7288 (Fig. $3 D$; wild type: $12.3 \pm 3.8 \mathrm{mV}^{\star} \mathrm{ms}$, fmr1 KO: $10.5 \pm$ $2.4 \mathrm{mV}^{\star} \mathrm{ms}$. Mann-Whitney, $\left.U=11, p=0.84\right)$. These results suggest that higher dendritic $\mathrm{I}_{\mathrm{h}}$ alone does not account for the lack of TA-LTP in fmr1 KO CA1 pyramidal neurons.

$\mathrm{Ca}^{2+}$ entry into fmr1 KO neurons is reduced at TA synapses A rise in intracellular $\mathrm{Ca}^{2+}$ during TBS is necessary for the induction of TA-LTP (Golding et al., 2002; Remondes and Schuman, 2003; Takahashi and Magee, 2009). We used two-photon imaging to directly measure changes in dendritic $\mathrm{Ca}^{2+}$ during TA TBS in wild-type and fmr1 KO CA1 neurons (Fig. 4A). We varied the initial EPSP amplitude and triggered bursts TA EPSPs (10 at $100 \mathrm{~Hz}$; Tsay et al., 2007). Small but detectable $\mathrm{Ca}^{2+}$ signals were observed at EPSP amplitudes $>1 \mathrm{mV}$ for both wildtype and $f m r 1 \mathrm{KO}$ neurons. In both wild-type and $f m r 1 \mathrm{KO}$ dendrites, the $\mathrm{Ca}^{2+}$ signal increased with increasing EPSP amplitude; however, the $\mathrm{Ca}^{2+}$ signal was smaller in fmrl $\mathrm{KO}$ compared with wild-type dendrites (Fig. $4 B, C$; wild type: $n=11$ from 8 mice; fmr1 KO: $n=10$ from 7 mice; two-way RM ANOVA, $F_{(1,19)}=13.14, p=0.002, \eta^{2}=0.13$. Interaction, $F_{(2,38)}=4.86, p=$ $0.013, \eta^{2}=0.1$. Sidak's test, $4 \mathrm{mV}: p=0.04, \eta^{2}=0.29$; wild type: $52.73 \pm 13.38 \Delta \mathrm{F} / \mathrm{F} ;$ fmr1 KO: $12.26 \pm 2.77 \Delta \mathrm{F} / \mathrm{F})$.

\section{NMDAR-mediated EPSPs are not different between wild- type and $f m r 1$ KO TA synapses}

NMDAR activation is a key source of $\mathrm{Ca}^{2+}$ influx during the induction of TA-LTP (Golding et al., 2002; Remondes and Schuman, 2003; Takahashi and Magee, 2009). Although we previously showed that there was no significant difference in TA EPSPs between wild-type and fmr1 KO CA1 neurons (Fig. 1), those experiments did not separate the AMPA and NMDAR contributions to the EPSP. To test whether NMDAR-mediated EPSPs are different between wild-type and fmr $1 \mathrm{KO}$ neurons, we stimulated TA inputs in the presence of AMPA receptor blocker DNQX $(20 \mu \mathrm{M})$ and with $0 \mathrm{mM} \mathrm{Mg}^{2+}$ in the extracellular saline (Fig. 4D, left). Application of the NMDAR antagonist D-AP5 $(50 \mu \mathrm{M})$ confirmed isolation of NMDARmediated EPSPs in a subset of experiments (Fig. 4D, right). In agreement with our data in Figure $1 E$, we found no difference in isolated NMDAR-mediated TA EPSPs between wildtype and $f m r 1 \mathrm{KO}$ CA1 pyramidal neurons (Fig. 4E; wild type: $n=7$ from 3 mice; fmr 1 KO: $n=7$ from 3 mice; twoway RM ANOVA, $\left.F_{(1,12)}=0.19, p=0.87\right)$.

Dendritic recordings of TA synaptic transmission and LTP Using somatic recordings, we showed a clear lack of TA-LTP in fmr1 KO CA1 pyramidal neurons, and dendritic imaging revealed reduced dendritic $\mathrm{Ca}^{2+}$ influx during bursts of TA stimulation. This suggests that the dendrites are the locus of the changes that impair TA-LTP in fmr1 KO CA1 pyramidal neurons. Many of the dendritic events required for TA-LTP are distorted or undetectable using somatic recording because of the filtering properties of CA1 dendrites. Thus, we performed current-clamp recordings from the apical dendrites of wild-type and fmr1 KO CA1 pyramidal neurons (Fig. 5A; $40 \mu \mathrm{M}$ Alexa Fluor 594; distance from soma, wild type: $211.8 \pm 3.52 \mu \mathrm{m}$; fmr1 KO $212.1 \pm 4.69 \mu \mathrm{m}$; Mann-Whitney, $U=99.5, p=0.84$ ). Consistent with our somatic recordings, TA EPSP slope was significantly increased post-TBS in wild-type but not fmr1 KO 


\section{Dendritic Calcium Imaging}
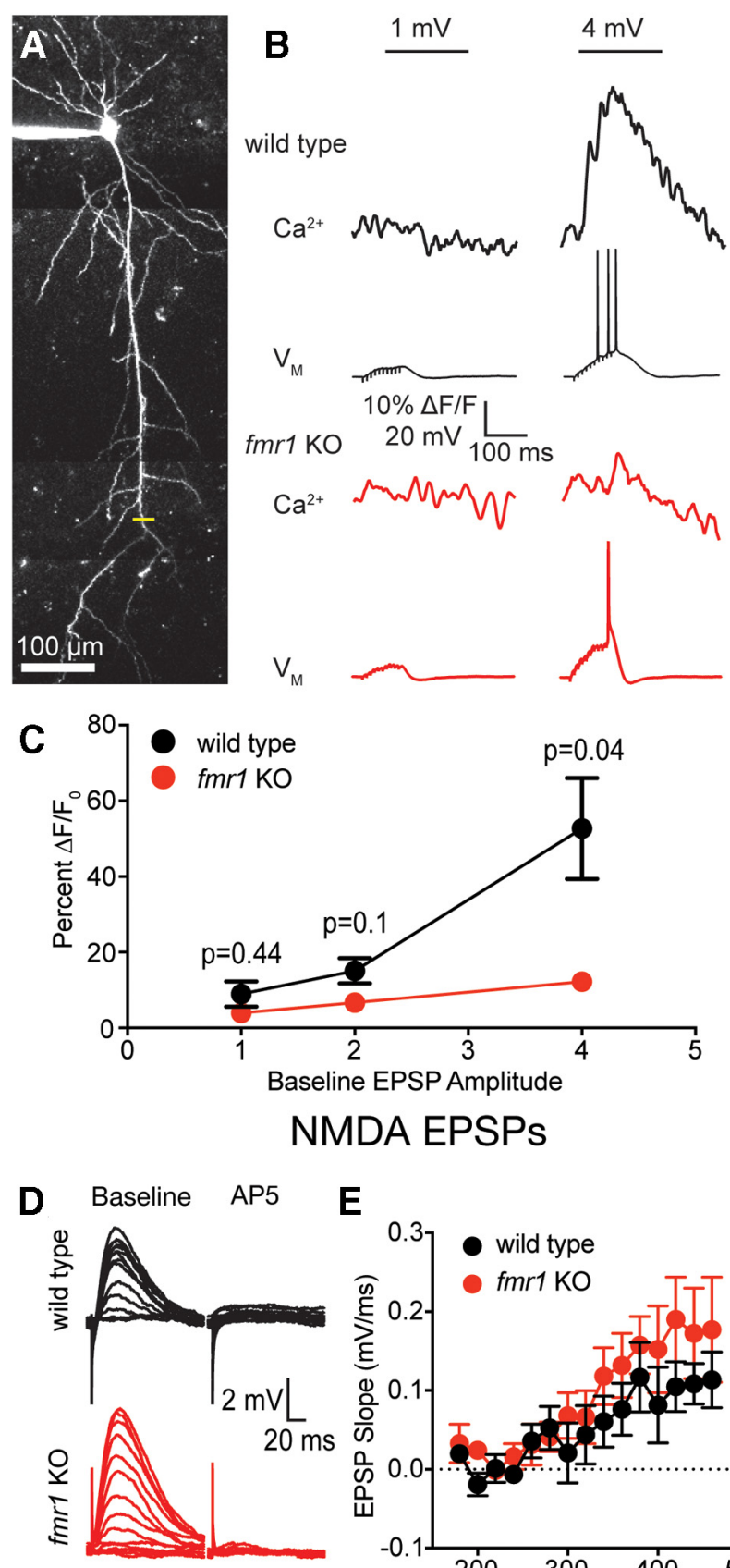

E

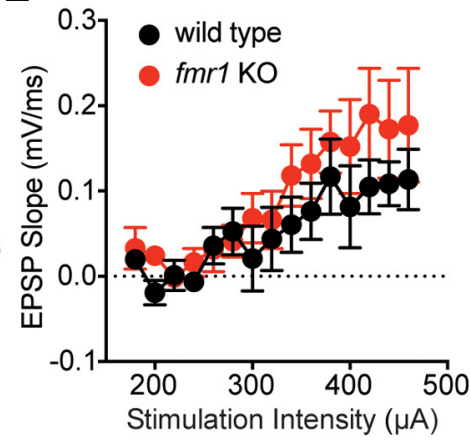

Figure 4. Synaptic $\mathrm{Ca}^{2+}$ signaling reduced in $\mathrm{fmr} 1 \mathrm{KO}$ dendrites. $\boldsymbol{A}$, Representative CA1 neuron filled with OGB-1 (100 $\mu \mathrm{m})$ and Alexa $594(40 \mu \mathrm{M})$. Yellow bar represents location of line scan imaging in the s.l.m region. $\boldsymbol{B}$, Representative $\mathrm{Ca}^{2+}$ and voltage signals during $100 \mathrm{~Hz}$ bursts of TA EPSPs using 1 and $4 \mathrm{mV}$ initial EPSP amplitudes. C, Group data of peak intracellular $\mathrm{Ca}^{2+}$ signal during bursts of synaptic activity as a function of initial EPSP amplitude (two-way RM ANOVA, $F_{(1,19)}=13.14, p=0.002, \eta^{2}=0.13$. Interaction, $F_{(2,38)}, 4.86, p=$ $0.013, \eta^{2} 0.1$. Sidak's test, $\left.4 \mathrm{mV}, p=0.04\right)$. $\boldsymbol{D}$, Representative input output traces of NMDARdependent EPSPs in $0 \mathrm{~mm} \mathrm{Mg}{ }^{2+}$ and the AMPA blocker DNQX (20 $\mu \mathrm{m}$; left). Addition of the NMDAR antagonist AP5 $(25 \mu \mathrm{m})$ confirmed the synaptic response was NMDAR dependent (right). $\boldsymbol{E}$, Slope of NMDAR EPSPs as a function of stimulation intensity was not different between wild-type and fmr1 K0 neurons (two-way RM ANOVA, $F_{(1,12)}=0.19, p=0.87$ ).

neurons (Fig. 5B,C; wild type: $n=8$ from 4 mice; pre-TBS: 0.65 $\pm 0.15 \mathrm{mV} / \mathrm{ms}$, post-TBS: $2.74 \pm 0.59 \mathrm{mV} / \mathrm{ms}$. Wilcoxon, $W=$ $36, p=0.008, \eta^{2}=0.4$; fmr 1 KO: $n=7$ from 4 mice; pre-TBS: $0.65 \pm 0.11 \mathrm{mV} / \mathrm{ms}$, post-TBS: $1.01 \pm 0.18 \mathrm{mV} / \mathrm{ms}$. Wilcoxon,
$W=18, p=0.16)$. There was no difference in the area under the curve during TBS of TA synapses between wild-type and fmr 1 KO CA1 pyramidal neurons (Fig. $5 D$; wild type: $13.33 \pm$ $3.14 \mathrm{mV}^{\star} \mathrm{ms}$, fmrl KO: $8.78 \pm 3.76 \mathrm{mV}^{\star} \mathrm{ms}$. Mann-Whitney, $U$ $=16, p=0.19$ ). There was no significant difference in the response to single stimuli (Fig. $5 E$; wild type: $n=6$ from 2 mice; fmr1 KO: $n=7$ from 4 mice; two-way RM ANOVA, $F_{(1,17)}=$ $0.63, p=0.44$ ), paired-pulse ratio (Fig. $5 F$; wild type: $n=7$ from 4 mice; fmrl KO: $n=7$ from 4 mice; two-way RM ANOVA, $F_{(1,12)}=0.022, p=0.88$ ), or summation (Fig. $5 G$; wild type: $n=6$ from 2 mice; fmr1 KO: $n=7$ from 4 mice; two-way RM ANOVA, $\left.F_{(1,12)}=0.00,001, p=0.99\right)$ between wild-type and fmr1 KO CA1 neurons. Paired-pulse ratios were not different after TBS (wild type: two-way RM ANOVA, $F_{(1,6)}=1.89, p=0.22$; fmr1 KO: two-way RM ANOVA, $\left.F_{(1,6)}=0.02, p=0.89\right)$. Dendritic recordings, much like in somatic recordings, show a lack of fmr1 KO TA-LTP. We next used dendritic recording to investigate suprathreshold dendritic events implicated in TALTP.

Dendritic complex and $\mathrm{Ca}^{2+}$ spikes are not different between wild-type and fmr $1 \mathrm{KO}$ neurons

NMDARs, activated by presynaptic glutamate release, are one source of $\mathrm{Ca}^{2+}$ signaling. We found that subthreshold NMDARmediated EPSPs activated by stimulation of TA synapses were not different between wild-type and $f m r 1$ KO neurons. Dendritic voltage-gated channels can also contribute to rises in dendritic $\mathrm{Ca}^{2+}$ (Magee and Johnston, 1995; Golding et al., 2002; Remondes and Schuman, 2003; Takahashi and Magee, 2009). The activation of distal synapses in CA1 pyramidal neurons gives rise to complex spikes in CA1 dendrites mediated by voltage-gated $\mathrm{Na}^{+}$and $\mathrm{Ca}^{2+}$ channels (Andreasen and Lambert, 1995; Golding and Spruston, 1998; Golding et al., 1999; Takahashi and Magee, 2009; Kim et al., 2015). We therefore tested the hypothesis that complex spikes and $\mathrm{Ca}^{2+}$-dependent action potentials are impaired in $\mathrm{fmrl} \mathrm{KO}$ neurons.

In CA1 pyramidal neurons, dendritic complex spikes consist of a fast initial $\mathrm{Na}^{+}$spike that triggers $1-3$ slower $\mathrm{Ca}^{2+}$ mediated spikes (Golding et al., 1999). We used dendritic current injection (1 s) to compare complex spikes between wild-type and fmr1 KO CA1 neurons (Fig. 6A). Previous studies using rat hippocampus showed that only a subpopulation of CA1 dendrites fire complex spikes (Andreasen and Lambert, 1995; Golding et al., 1999). We found that approximately half of mouse CA1 neurons fired complex spikes and that the proportion was not different between wild-type and fmrl KO CA1 pyramidal neurons (wild type: $51.6 \%$, fmr1 KO: $47.6 \%$ ). There was no difference in the width of the complex spikes between wild-type and fmr1 KO CA1 dendrites (Fig. $6 B-D$; wild type: $n=16$ from 14 mice; fmr 1 KO: $n=$ 11 from 10 mice; two-way RM ANOVA, $F_{(1,24)}=0.00,002, p=$ 0.67; Takahashi and Magee, 2009). To isolate the dendritic $\mathrm{Ca}^{2+}$ spike component of the complex spike, we applied $0.5 \mu \mathrm{M}$ TTX to block voltage-gated $\mathrm{Na}^{+}$channels and $50 \mu \mathrm{M} 4$-AP to block voltage-gated $\mathrm{K}^{+}$channels and bias the dendrites toward firing dendritic $\mathrm{Ca}^{2+}$ spikes (Benardo et al., 1982; Andreasen and Lambert, 1995; Golding et al., 1999). Dendritic $\mathrm{Ca}^{2+}$ spikes were evoked by depolarizing current injections and confirmed to be mediated by voltage-gated $\mathrm{Ca}^{2+}$ channels by the addition of 200 $\mu \mathrm{M} \mathrm{Cd}{ }^{2+}$ (Fig. 6E). The number of elicited $\mathrm{Ca}^{2+}$ spikes was not different between wild-type and $f m r 1 \mathrm{KO} C A 1$ pyramidal neuron dendrites (Fig. 6F). The first $\mathrm{Ca}^{2+}$ spike elicited was selected for further analysis (Fig. $6 G-K$ ). Dendritic $\mathrm{Ca}^{2+}$ spike amplitude 

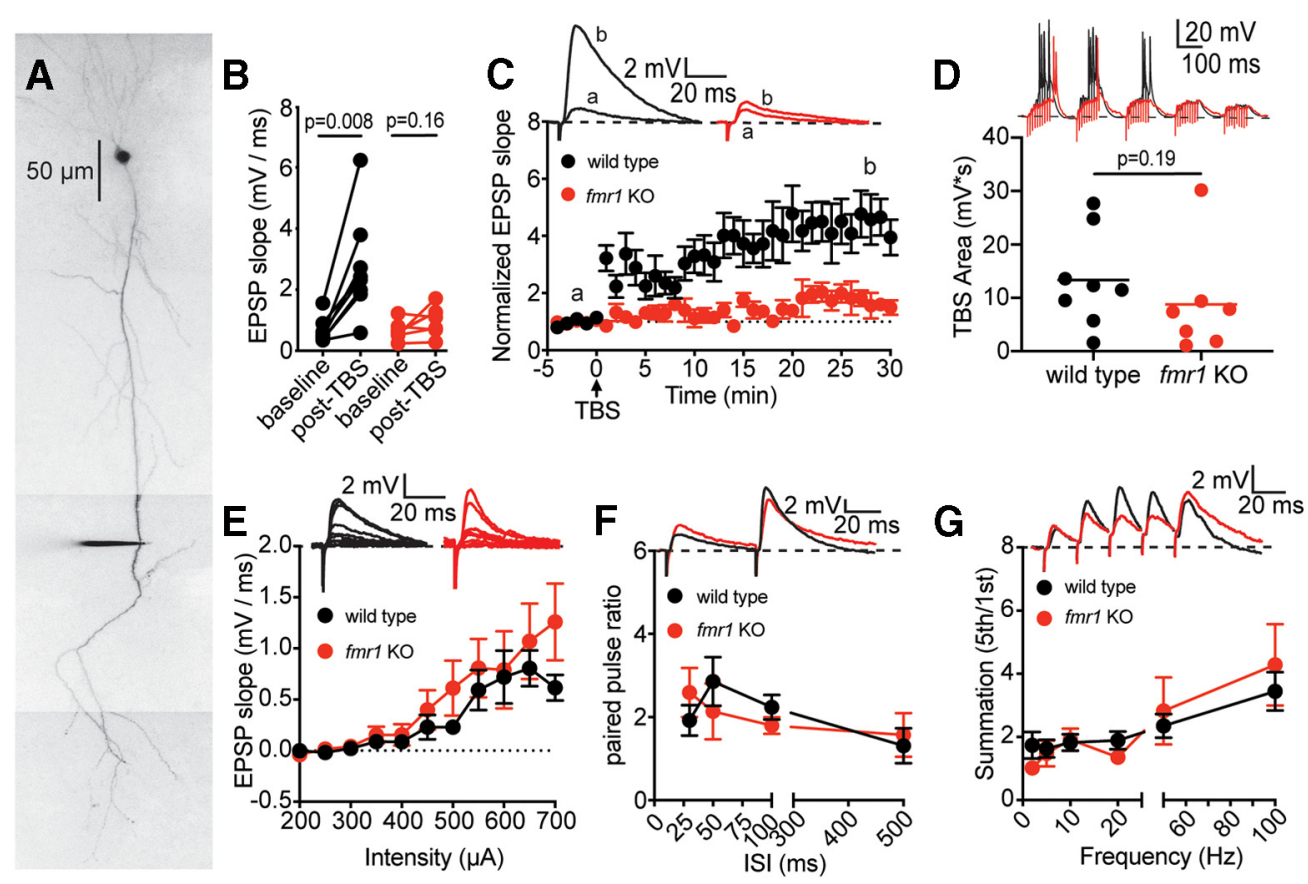

Figure 5. Dendritic recordings show a lack of TA-LTP in fmr $1 \mathrm{KO}$ CA1 pyramidal neurons. $A$, Representative dendritic recording from a CA1 neuron filled with Alexa Fluor 594 (40 $\mu \mathrm{m})$. $\boldsymbol{B}$, EPSP slope is increased 30 min post-TBS in wild-type but not fmr1 KO CA1 neurons (wild type: Wilcoxon, $W=36, p=0.008, \eta^{2}=0.4$; fmr1 K0: Wilcoxon, $W=18, p=0.16$ ). $C$, Normalized EPSP change in EPSP slope for wild-type and fmr1 KO CA1 neurons. Inset, Representative EPSP traces from baseline (a) and post-TBS (b). D, Graph of area under the curve during TBS (MannWhitney, $U=16, p=0.19)$. $\boldsymbol{E}$, Input output of EPSP slope at TA inputs in dendritic recordings (two-way RM ANOVA, $F_{(1,17)}=0.63, p=0.44$ ). Inset, Representative dendritic experiments. $\boldsymbol{F}$, Paired-pulse ratio is not different between wild-type and fmr1 KO CA1 pyramidal neurons (two-way RM ANOVA, $F_{(1,12)}=0.022, p=0.88$ ). Inset, 50 ms ISI paired pulse. $\mathbf{G}$, Temporal summation is not different between wild-type and fmr1 KO CA1 pyramidal neurons (two-way RM ANOVA, $F_{(1,12)}=0.00,001, p=0.99$ ). Inset, $50 \mathrm{~Hz}$ temporal summation experiment.

(Fig. $6 H$; wild type: $n=6$ from 5 mice, $35.32 \pm 1.08 \mathrm{mV}$; fmr 1 KO: $n=7$ from 6 mice, $38.08 \pm 1.84 \mathrm{mV}$; Mann-Whitney, $U=$ 9, $p=0.18$ ), maximum rate of rise (Fig. $6 I$; wild type: $7.66 \pm$ $1.06 \mathrm{mV} / \mathrm{ms}, \mathrm{fmrl} \mathrm{KO}: 7.79 \pm 0.51 \mathrm{mV} / \mathrm{ms}$. Mann-Whitney, $U=20.5, p=0.98$ ), maximum rate of decay (Fig. 6 J; wild type: $-4.52 \pm 0.70 \mathrm{mV} / \mathrm{ms}$, fmr1 KO: $-4.22 \pm-2.80 \mathrm{mV} / \mathrm{ms}$. MannWhitney, $U=19, p=0.84$ ) and estimated threshold (Fig. $6 \mathrm{~K}$; wild type: $-16.47 \pm 2.25 \mathrm{mV}, f m r 1 \mathrm{KO}:-14.98 \pm 3.76 \mathrm{mV}$. Mann-Whitney, $U=19, p=0.84$ ) were not different between wild-type and fmrl KO neurons. These results suggest that impairment of dendritic complex spikes or $\mathrm{Ca}^{2+}$ spikes does not contribute to the reduced dendritic $\mathrm{Ca}^{2+}$ signal in $f m r 1 \mathrm{KO} C A 1$ pyramidal neuron bursts of TA stimulation.

\section{Block of inwardly rectifying $\mathrm{K}^{+}$channels rescues TA-LTP in fmr1 KO neurons}

Our results thus far suggest that there are no differences in NMDARs at TA synapses, dendritic complex spikes, or dendritic $\mathrm{Ca}^{2+}$ spikes between wild-type and fmr1 KO CA1 pyramidal neurons. Furthermore, despite higher dendritic expression, block of $\mathrm{I}_{\mathrm{h}}$ in fmr1 KO neurons does not rescue TA-LTP. Inwardly rectifying $\mathrm{K}^{+}\left(\mathrm{K}_{\mathrm{IR}}\right)$ channels are open at or near the resting membrane potential, expressed in CA1 pyramidal neuron dendrites, and contribute to the induction of hippocampal LTP (Hoffman et al., 1997; Chen and Johnston, 2004; Malik and Johnston, 2017). In rats, $K_{I R}$ channels in the dendrites constrain dendritic nonlinear events and control LTP (Malik and Johnston, 2017). To test whether $\mathrm{K}_{\mathrm{IR}}$ channels contribute to the lack of TA-LTP in fmr1 KO neurons, we performed TBS TA-LTP experiments in the presence of $25 \mu \mathrm{M} \mathrm{Ba}^{2+}$ to block $\mathrm{K}_{\mathrm{IR}} \mathrm{S}$ (Malik and Johnston, 2017; Fig. 7A). Block of $\mathrm{K}_{\mathrm{IR}}$ rescued TA-LTP in fmr1 KO CA1 pyramidal neurons (Figure $7 B, C$; wild type: $n=5$ from 4 mice;
pre-TBS: $0.16 \pm 0.029 \mathrm{mV} / \mathrm{ms}$, post-TBS: $0.37 \pm 0.98 \mathrm{mV} / \mathrm{ms}$. Wilcoxon, $W=15, p=0.03, \eta^{2}=0.81$; $m r 1$ KO: $n=6$ from 3 mice; pre-TBS: $0.11 \pm 0.015 \mathrm{mV} / \mathrm{ms}$, post-TBS: $0.31 \pm 0.05 \mathrm{mV} /$ ms. Wilcoxon, $\left.W=21, p=0.03, \eta^{2}=0.81\right)$. The area under the curve during the induction protocol was not different between wild-type and fmr1 KO CA1 pyramidal neurons in the presence of $25 \mu \mathrm{M} \mathrm{Ba}^{2+}$ (Fig. $7 D$; wild type: $21.89 \pm 8.17 \mathrm{mV}^{\star} \mathrm{ms}$, fmr 1 KO: $9.78 \pm 1.49 \mathrm{mV}^{\star} \mathrm{ms}$. Mann-Whitney, $U=11, p=0.54$ ).

One potential explanation for the rescue of TA-LTP by $\mathrm{Ba}^{2+}$ is that there is a higher dendritic expression of $\mathrm{K}_{\mathrm{IR}} \mathrm{S}$ in $f m r 1 \mathrm{KO}$ CA1 pyramidal neurons. To test whether dendritic $\mathrm{K}_{\mathrm{IR}} \mathrm{s}$ were different between wild-type and fmrl KO CA1 neurons, we measured the dendritic resting membrane potential $\left(\mathrm{V}_{\mathrm{m}}\right)$ and input resistance $\left(\mathrm{R}_{\mathrm{N}}\right)$ before and after application of 25 $\mu \mathrm{M} \mathrm{Ba}^{2+}$ (Fig. 7E). Extracellular $\mathrm{Ba}^{2+}$ depolarized $\mathrm{V}_{\mathrm{M}}$ in both wild-type and fmr1 KO dendrites (Fig. $7 F$; wild type: $n=7$ from 3 mice; pre- $\mathrm{Ba}^{2+}:-59.29 \pm 2.53 \mathrm{mV}$, post-Ba ${ }^{2+}$ : $-55.29 \pm 2.47 \mathrm{mV}$. Wilcoxon, $W=28, p=0.016, \eta^{2}=0.79$; fmr1 KO: $n=7$ from 2 mice; pre-Ba ${ }^{2+}:-59.86 \pm 1.68 \mathrm{mV}$, post- $\mathrm{Ba}^{2+}:-54.00 \pm 1.6 \mathrm{mV}$. Wilcoxon, $W=28, p=0.016$, $\left.\eta^{2}=0.79\right)$. The effect of $\mathrm{Ba}^{2+}$ on $\mathrm{V}_{\mathrm{M}}$ was however, not significantly different between wild-type and fmr1 KO neurons (Fig. $7 G$; wild type: $4.00 \pm 1.02 \mathrm{mV}, f m r 1 \mathrm{KO}: 5.86 \pm$ $0.94 \mathrm{mV}$. Mann-Whitney, $U=13.5, p=0.16)$. Extracellular $\mathrm{Ba}^{2+}$ also increased $\mathrm{R}_{\mathrm{N}}$ in both wild-type and $f m r 1 \mathrm{KO}$ dendrites (Fig. $7 H$,I; wild type: $n=7$ from 3 mice; two-way RM ANOVA, $F_{(1,5)}=11.81, p=0.019, \eta^{2}=0.12$; fmr1 KO: $n=7$ from 2 mice; two-way RM ANOVA, $F_{(1,6)}=10.13, p=0.019$, $\left.\eta^{2}=0.1\right)$. As for $\mathrm{V}_{\mathrm{M}}$, the change in $\mathrm{R}_{\mathrm{N}}$ was not significantly different between wild-type and $f m r 1 \mathrm{KO}$ dendrites (Fig. 7 J; two-way RM ANOVA, $\left.F_{(1,11)}=0.005, p=0.95\right)$. These results demonstrate that, although block of $\mathrm{K}_{\mathrm{IR}} \mathrm{s}$ by extracellular $\mathrm{Ba}^{2+}$ rescued TA-LTP in fmr1 KO neurons, the functional 


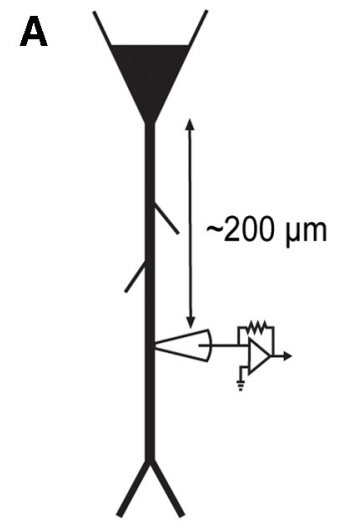

\section{Dendritic complex spikes}

\section{B 1 spike 2 spikes 3 spikes}
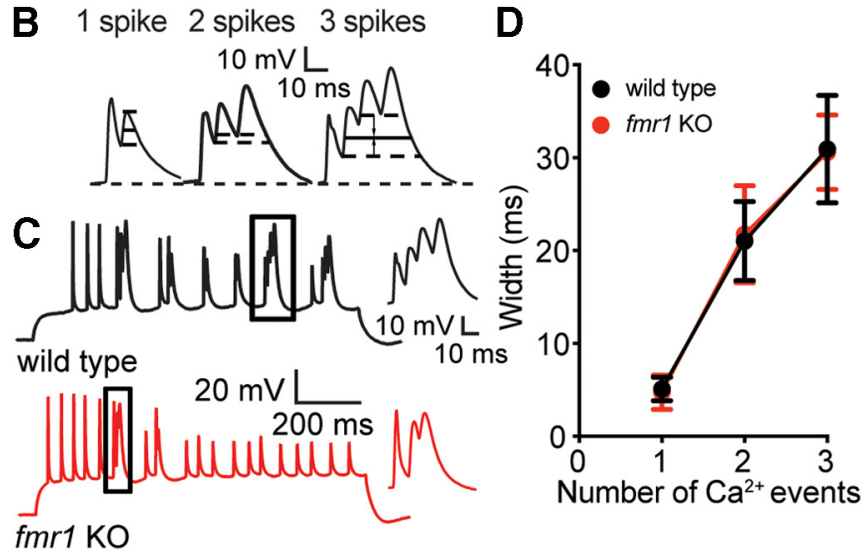

Number of $\mathrm{Ca}^{2+}$ events

fmr1 KO

\section{Dendritic calcium spikes}

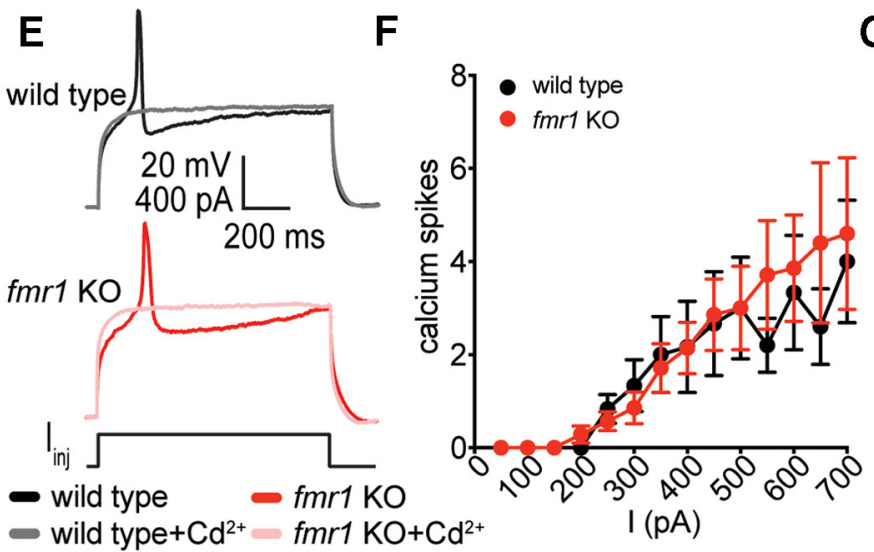

G
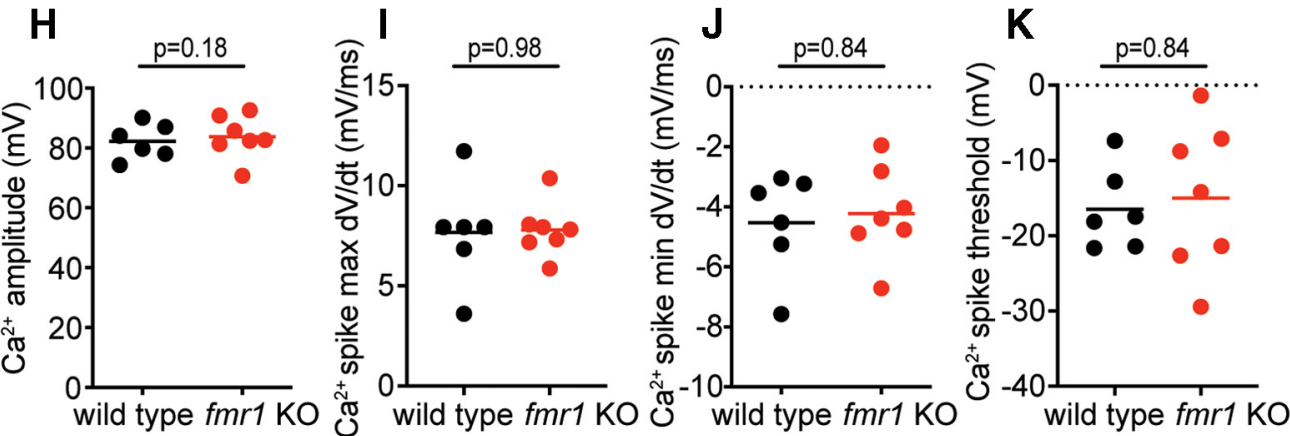

Figure 6. Dendritic complex and $\mathrm{Ca}^{2+}$ spikes are not different between wild-type and fmr $1 \mathrm{KO}$ CA1 pyramidal neurons. $\boldsymbol{A}$, Dendritic recording schematic. $\boldsymbol{B}$, Method for measuring complex spike width (see above, Materials and Methods). C, Complex spikes elicited by dendritic current injection in wild-type and fmr $1 \mathrm{KO}$ neurons (left) and example complex spikes (boxes) shown on expanded time scale (right). D, Complex spike width as a function of number of events (1-3; two-way RM ANOVA, $\left.F_{(1,24)}=0.00,002, p=0.67\right)$. $\boldsymbol{E}$, Representative traces of isolated dendritic $\mathrm{Ca}^{2+}$ spikes in the presence of $500 \mathrm{~nm} \mathrm{TTX}$ and $50 \mu \mathrm{m}$ 4-AP. Application of $200 \mu \mathrm{m} \mathrm{Cd}^{2+}$ confirmed that spikes were generated by voltage-gated Ca ${ }^{2+}$ channels. $\boldsymbol{F}$, The number of $\mathrm{Ca}^{2+}$ spikes as a function of current amplitude (two-way RM ANOVA, $\left.F_{(1,11)}=0.07, p=0.8\right)$. $\boldsymbol{G}, \boldsymbol{H}-\boldsymbol{K}$, Representative dendritic $\mathrm{Ca}^{2+}$ spike traces (left). Single $\mathrm{Ca}^{2+}$ spike in the box at left on expanded time scale used for analyses in $\boldsymbol{H}-\boldsymbol{K}$ (right). Black arrows show the estimated threshold. $\boldsymbol{H}-\boldsymbol{K}$, Dendritic $\mathrm{Ca}^{2+}$ spike amplitude $(\boldsymbol{H}$; Mann-Whitney, $\boldsymbol{U}=9, p=0.18)$, maximum rate of rise $(\boldsymbol{I}$; Mann-Whitney, $U=20.5, p=0.98)$, minimum rate of decay $(\boldsymbol{J}$; Mann-Whitney, $U=19, p=0.84)$, and threshold $(\boldsymbol{K}$; Mann-Whitney, $U=19, p=0.84)$ were not significantly different between wild-type and fmr1 K0 neurons.

expression of dendritic $\mathrm{K}_{\mathrm{IR}} \mathrm{s}$ is not different between wildtype and fmr $1 \mathrm{KO}$ CA1 pyramidal neurons.

\section{Dendritic depolarization rescues TA-LTP in fmr1 KO CA1} pyramidal neurons

The block of $\mathrm{K}_{\mathrm{IR}} \mathrm{s}$ depolarized dendritic $\mathrm{V}_{\mathrm{m}}$, increased dendritic $\mathrm{R}_{\mathrm{N}}$ and rescued TA-LTP. In rat CA1 neurons, direct manipulation of dendritic $V_{m}$ was able to reproduce the effects of $K_{I R} S$ on dendritic function (Malik and Johnston, 2017). To test whether the depolarization would mimic the effects of $\mathrm{Ba}^{2+}$ on TA-LTP, we depolarized the dendritic $V_{\mathrm{m}}$ by $10 \mathrm{mV}$ during the delivery of TBS using steady-state current injection to mimic the depolarization of oblique dendrites (Golding et al., 2005) during $\mathrm{Ba}^{2+}$ wash-on (Fig. 8A). Similar to extracellular $\mathrm{Ba}^{2+}$, dendritic depolarization rescued TA-LTP in $f m r 1 \mathrm{KO}$ neurons (Fig. $8 B, C$; wild type: $n=6$ from 2 mice; pre-TBS: $0.36 \pm 0.048 \mathrm{mV} / \mathrm{ms}$, postTBS: $1.21 \pm 0.16 \mathrm{mV} / \mathrm{ms}$. Wilcoxon, $W=21, p=0.03, \eta^{2}=0.4$; fmrl KO: $n=7$ from 4 mice; pre-TBS: $0.55 \pm 0.21 \mathrm{mV} / \mathrm{ms}$, postTBS: $2.22 \pm 0.61 \mathrm{mV} / \mathrm{ms}$. Wilcoxon, $W=24, p=0.047, \eta^{2}=$ 

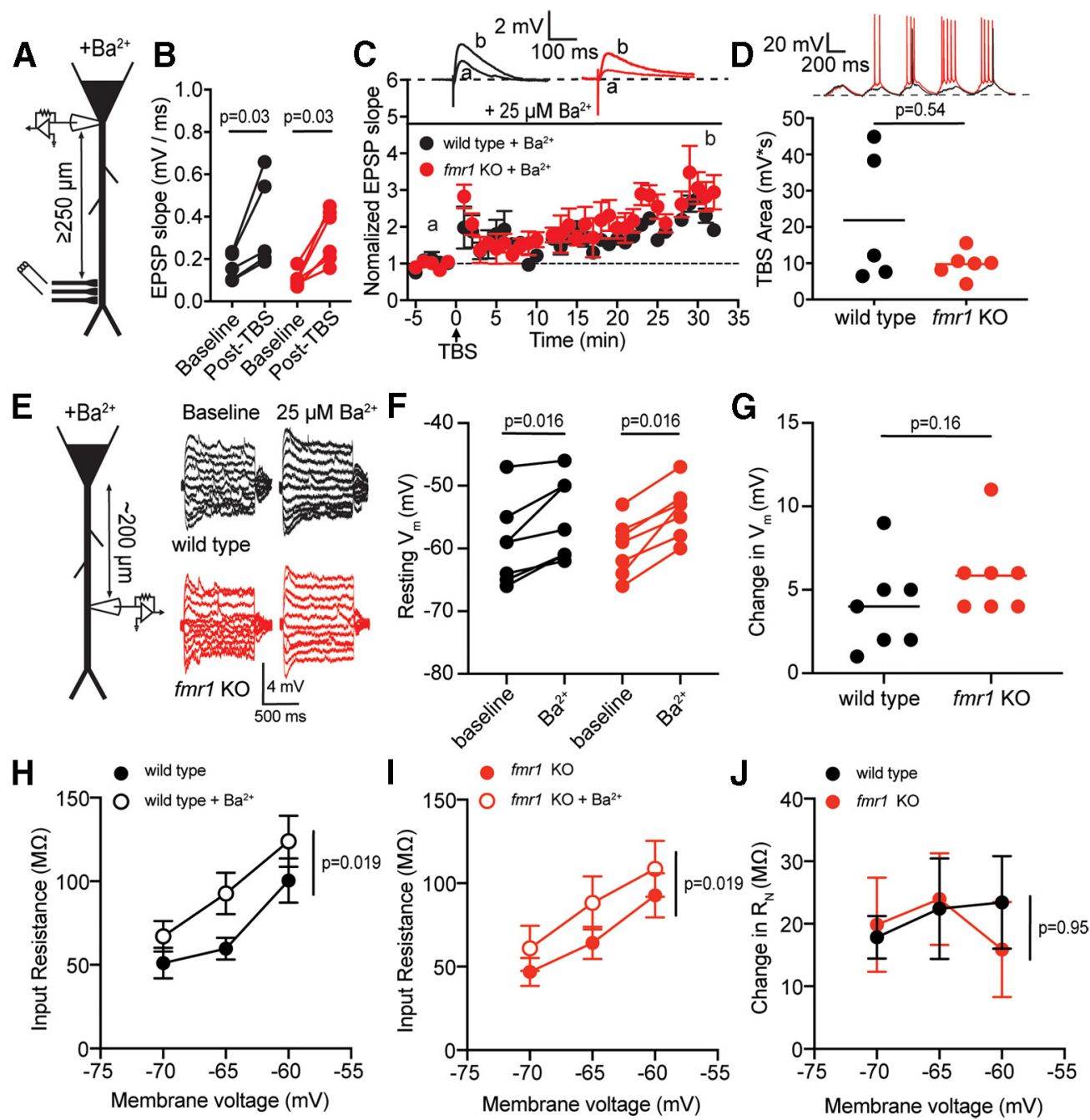

Figure 7. Low $\mathrm{Ba}^{2+}$ rescues TA-LTP in fmr $1 \mathrm{KO}$ CA1 pyramidal neurons. $\boldsymbol{A}$, Recording configuration during low $\mathrm{Ba}^{2+}{ }^{2}$ TA-LTP experiments. $\boldsymbol{B}$, EPSP slope is significantly increased 30 min after TBS in both wild-type and fmr1 KO CA1 neurons (wild type: Wilcoxon, $W=15, p=0.03, \eta^{2}=0.81$; fmr1 K0: Wilcoxon, $W=21, p=0.03, \eta^{2}=0.81$ ). C, Normalized change in EPSP slope for wild-type and fmr $1 \mathrm{KO}$ CA1 neurons in the presence of $25 \mu \mathrm{m}$ extracellular Ba ${ }^{2+}$. Inset, Baseline and post-TBS EPSP traces from wild-type and fmr $1 \mathrm{KO}$ neurons. $\boldsymbol{D}$, Graph of area under the curve during TBS with $\mathrm{Ba}^{2+}$ included in the bath saline (Mann-Whitney, $\left.U=11, p=0.54\right) \boldsymbol{E}$, Recording configuration (left) and representative voltage traces before and after application of $25 \mu \mathrm{M} \mathrm{Ba}{ }^{2+} . F_{,} \mathrm{Ba}^{2+}$ significantly depolarizes $\mathrm{V}_{\mathrm{M}}$ in both wild-type and fmr1 $\mathrm{KO}$ neurons (wild type: Wilcoxon, $W=28, p=0.016, \eta^{2}=0.79 ;$ fmr1 $\mathrm{K} 0$ : Wilcoxon, $W=28, p=0.016, \eta^{2}$ $=0.79)$. $G$, The effect of $\mathrm{Ba}^{2+}$ on $\mathrm{V}_{\mathrm{M}}$ is not different between wild-type and fmr $1 \mathrm{KO}$ neurons (Mann-Whitney, $\left.U=13.5, p=0.16\right)$. $\boldsymbol{H}, \boldsymbol{I}, \mathrm{Ba}^{2+}$ significantly increases $\mathrm{R}_{\mathrm{N}}$ in wild-type $(\boldsymbol{H}$; twoway RM ANOVA, $\left.F_{(1,5)}=11.81, p=0.019, \eta^{2}=0.12\right)$ and fmr1 K0 ( $\boldsymbol{l}$; two-way RM ANOVA, $\left.F_{(1,6)}=10.13, p=0.019, \eta^{2}=0.1\right)$ dendrites. $J$, The effect of $\mathrm{Ba}^{2+}$ on $\mathrm{R}_{\mathrm{N}}$ is not different between wild-type and fmr $1 \mathrm{KO}$ neurons (two-way RM ANOVA, $F_{(1,11)}=0.005, p=0.95$ ).

0.52). The area under the curve during the induction protocol was not different between wild-type and fmr1 KO CA1 pyramidal neurons (Fig. $8 D$; wild type: $8.65 \pm 1.08 \mathrm{mV}^{\star} \mathrm{ms}$, fmr1 KO: $15.22 \pm 3.6 \mathrm{mV} / \mathrm{ms}$. Mann-Whitney, $U=15, p=0.45)$. Unlike the $\mathrm{Ba}^{2+}$ experiments above, however, dendritic $\mathrm{V}_{\mathrm{m}}$ was only depolarized during delivery of the TBS. Together with $\mathrm{Ba}^{2+}$ wash-on experiments, these results suggest that fmr1 KO CA1 dendrites are unable to reach the threshold for TA-LTP induction under normal conditions.

\section{Dspike generation is impaired in fmr1 KO CA1 pyramidal neurons}

The large-scale, rapid influx of $\mathrm{Ca}^{2+}$ necessary for the generation of LTP at distal synapses in CA1 neurons is dependent on dendritic $\mathrm{Na}^{+}$spikes (Kim et al., 2015). Consequently, one explanation for our results thus far is that dspike generation is impaired in $f m r 1 \mathrm{KO}$ neurons. We used a double exponential current injection $\left(\tau_{\text {rise }}=0.1 \mathrm{~ms} ; \tau_{\text {decay }}=2 \mathrm{~ms}\right)$ to mimic the time course of dendritic EPSPs and trigger dendritic $\mathrm{Na}^{+}$spikes in wild-type and fmr1 KO dendrites (Fig. 9A; Gasparini et al., 2004). Figure $9 B$ shows dspike threshold as a function of the dendritic recording distance from the soma in wild-type and fmr1 KO CA1 neurons. Dspikes in fmr1 KO CA1 neurons had a more depolarized threshold (Fig. 9C; wild type: $n=7$ from 5 mice; fmr1 KO: $n=7$ from 5 mice; wild type: $-48.08 \pm 1.35 \mathrm{mV}$, fmr1 KO: $-41.48 \pm$ $1.87 \mathrm{mV}$. Mann-Whitney, $U=6, p=0.02, \eta^{2}=0.34$ ) and slower maximum dV/dt (Fig. 9D; wild type: $60.07 \pm 5.14 \mathrm{mV} / \mathrm{ms}, \mathrm{fmr} 1$ KO: $44.89 \pm 2.40 \mathrm{mV} / \mathrm{ms}$. Mann-Whitney, $U=3, p 0.004, \eta^{2}=$ $0.54)$ compared with wild-type dendrites.

\section{Dendritic voltage-gated $\mathrm{Na}^{+}$channels do not differ between wild-type and fmr1 KO CA1 neurons}

CA1 pyramidal neuron dendrites express voltage-gated $\mathrm{Na}^{+}$ channels, which contribute to dspikes (Magee and Johnston, 1995; Golding and Spruston, 1998). The difference in threshold and maximum $\mathrm{dV} / \mathrm{dt}$ could be accounted for by differences in dendritic voltage-gated $\mathrm{Na}^{+}$channels between wild-type and 


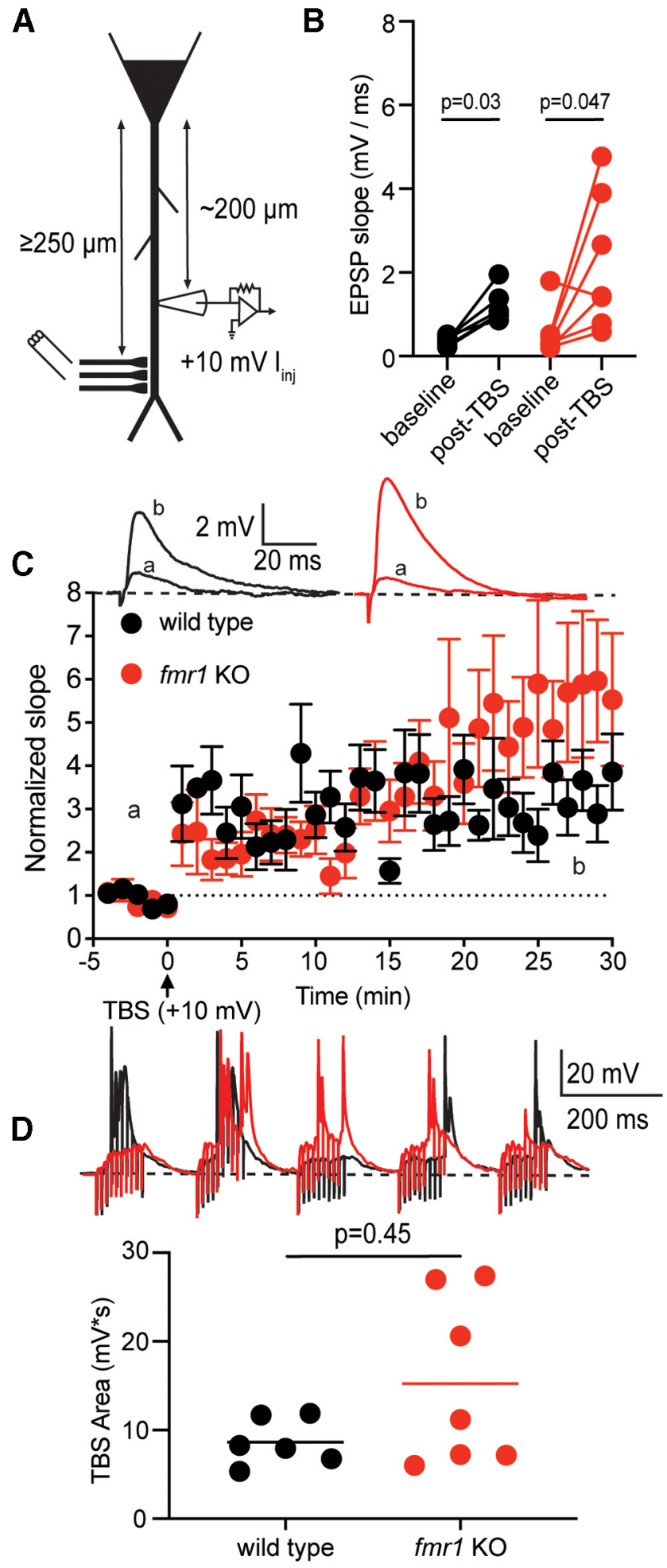

Figure 8. Dendritic depolarization rescues TA-LTP in fmr1 KO CA1 neurons. $\boldsymbol{A}$, Recording configuration. Current injection produced a $10 \mathrm{mV}$ depolarization during TBS. $\boldsymbol{B}$, EPSP slope is significantly increased $30 \mathrm{~min}$ after TBS in both wild-type and fmr1 KO CA1 neurons (wild type: Wilcoxon, $W=21, p=0.03, \eta^{2}=0.4$; fmr1 KO: Wilcoxon, $W=24, p=0.047, \eta^{2}$ $=0.52$ ). C, Normalized EPSP slope 5 min before and 30 min after TBS of TA inputs. Inset, Representative baseline and post-TBS EPSPs from wild-type and fmr1 K0 CA1 neurons. D, Graph of area under the curve during TBS while a steady depolarizing current of $10 \mathrm{mV}$ was applied to the dendritic patch (Mann-Whitney, $U=15, p=0.45$ ).
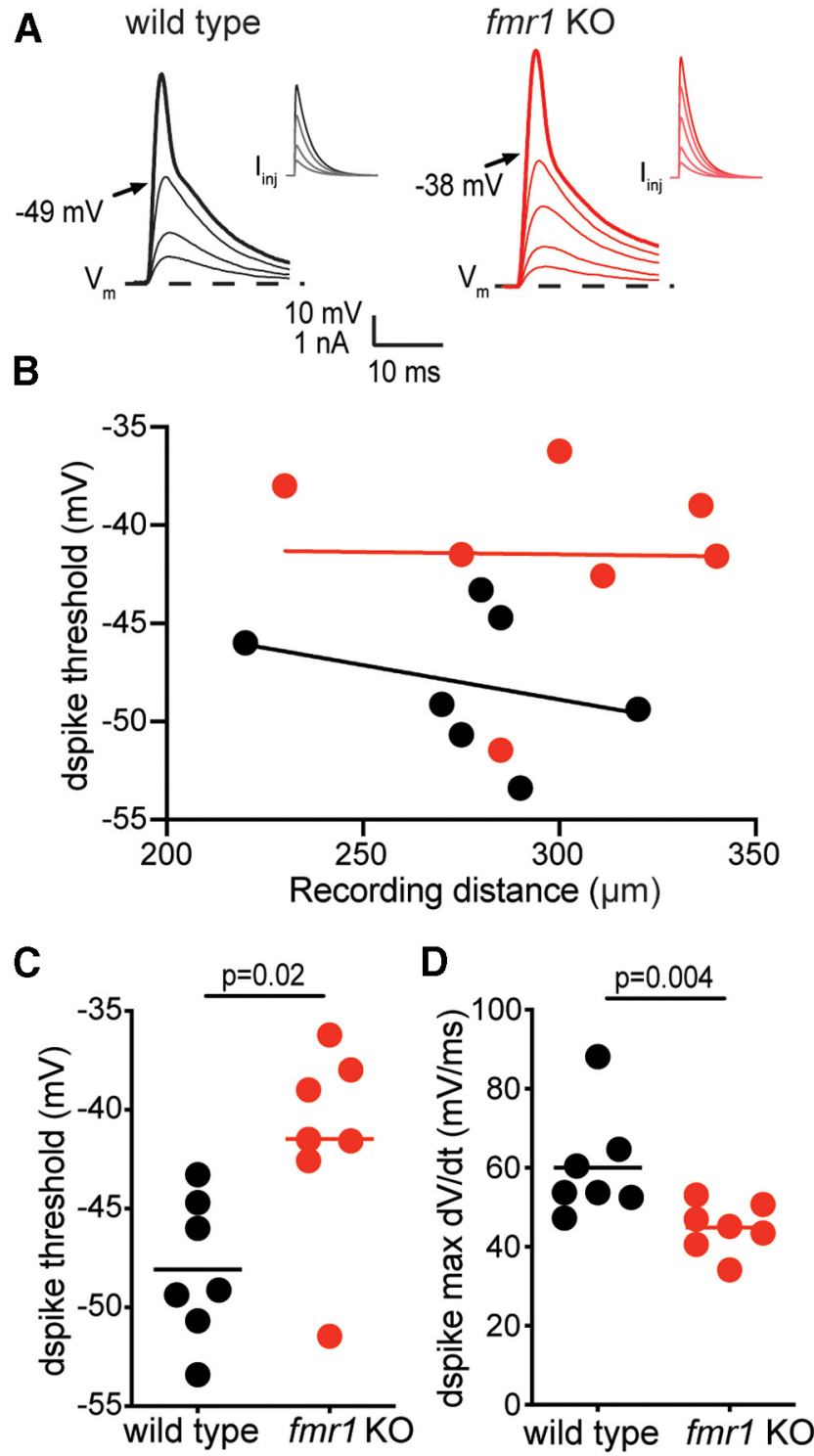

Figure 9. Dspike threshold is more depolarized in fmr1 K0 CA1 pyramidal neurons. $\boldsymbol{A}$, Dendritic voltage response to double exponential current injections (inset) of increasing amplitude (500 pA intervals). Thick lines show voltage traces with dspike and the corresponding current injection. $\boldsymbol{B}$, Graph of distance of dendritic recordings as a function of dspike threshold. $C$, Voltage threshold for dspikes is more depolarized in fmr1 KO CA1 neurons (MannWhitney, $\left.U=6, p=0.02, \eta^{2}=0.34\right)$. $D$, The maximum rate of rise is significantly slower in fmr1 KO neurons (Mann-Whitney, $U=3, p=0.004, \eta^{2}=0.54$ ).

fmr1 KO CA1 neurons. To test whether there are differences in dendritic $\mathrm{Na}^{+}$channel function, we measured $\mathrm{Na}^{+}$current using cell-attached voltage-clamp recordings from wild-type and fmr 1 KO dendrites (200-250 $\mu \mathrm{m}$ from the soma). The maximum current and voltage-dependence of $\mathrm{Na}^{+}$channels we measured in wild-type CA1 pyramidal neurons were in good agreement with those obtained from rat CA1 dendrites (Magee and Johnston, 1995; Gasparini and Magee, 2002). We found no difference in the $\mathrm{Na}^{+} I-V$ curve between wild-type and fmr1 KO neurons (Fig. 10A). Additionally, there was no significant difference in the voltage dependence of activation or steady-state inactivation between wild-type and $f m r 1 \mathrm{KO} \mathrm{Na}^{+}$channels (Fig. 10B). There was no difference in either the $\mathrm{V}_{1 / 2}$ of activation (Fig. 10C; wild type: $n=10$ from 3 mice, $-19.11 \pm 2.17 \mathrm{mV}$; fmr 1 KO: $n=8$ from 3 mice, $-16.2 \pm 4.23 \mathrm{mV}$. Mann-Whitney, $U=33, p=$ 0.57 ) or the activation slope factor (Fig. $10 D$; wild type: $7.15 \pm$ 
A

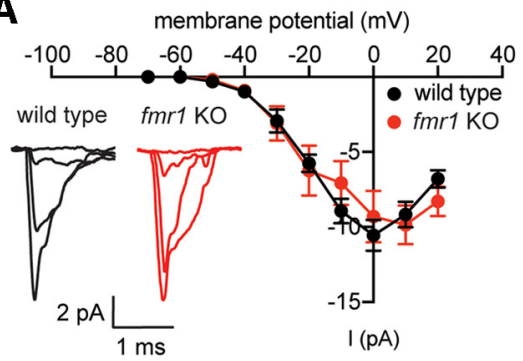

B
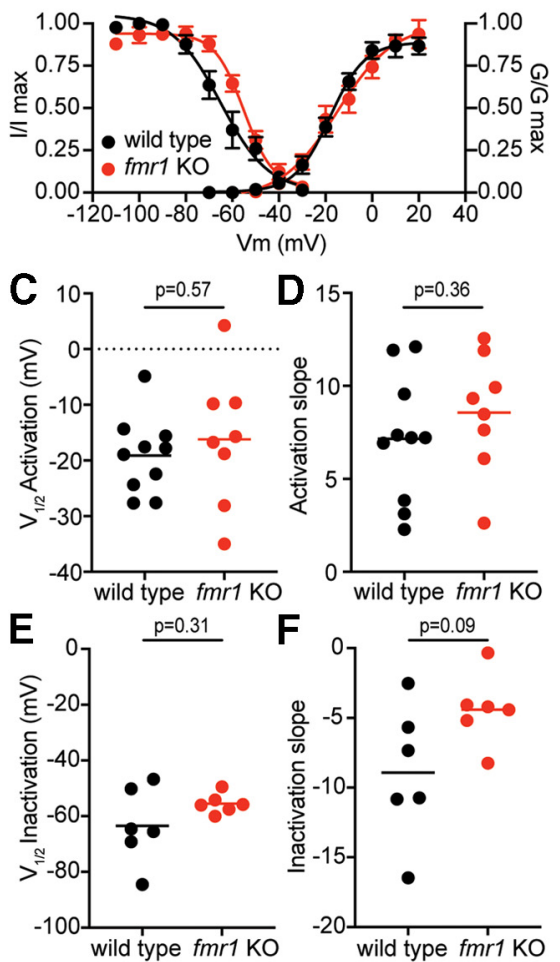

Figure 10. Dendritic $\mathrm{Na}^{+}$channels are not different between wild-type and fmr1 $\mathrm{KO}$ CA1 pyramidal neurons. $A$, Current-voltage plot showing no significant difference in $\mathrm{Na}^{+}$current between wild-type and $f m r 1 \mathrm{KO}$ dendrites. Inset, Representative $\mathrm{Na}^{+}$current traces in response to voltage steps to $-60,-40,-20$, and $0 \mathrm{mV} . \boldsymbol{B}_{,} \mathrm{Na}^{+}$channel activation and inactivation are not different between wild-type and fmr $1 \mathrm{KO} C \mathrm{CA} 1$ dendrites. $\boldsymbol{C}, \boldsymbol{D}, \mathrm{Na}^{+}$channel activation V1/2 (C, Mann-Whitney, $U=33, p=0.57$ ) and slope factor ( $\boldsymbol{D}$; Mann-Whitney, $U=29, p=$ 0.36) are not different between wild-type and $f m r 1 \mathrm{KO}$ dendrites. $\boldsymbol{E}, \boldsymbol{F}, \mathrm{Na}^{+}$channel steadystate inactivation V1/2 $(\boldsymbol{E}$; Mann-Whitney, $U=11, p=0.31)$ and slope factor $(\boldsymbol{F}$; MannWhitney, $U=7, p=0.09$ ) are not different between wild-type and fmr $1 \mathrm{KO}$ dendrites.

1.08. fmr1 KO: $8.57 \pm 1.13$, Mann-Whitney, $U=29, p=0.36$ ) between wild-type and $f m r 1 \mathrm{KO}$ CA1 pyramidal dendrites. Similarly, steady-state inactivation properties of $\mathrm{V}_{1 / 2}$ of inactivation (Fig. 10E; wild type: $n=6$ from 2 animals, $-63.47 \pm 5.59$. fmrl KO: $n=6$ from 2 animals, $-55.51 \pm 1.45$. Mann-Whitney, $U=11, p=0.31$ ) and inactivation slope (Fig. 10F; wild type: $n=$ 6 from 2 mice, $-8.93 \pm 1.98$; fmr 1 KO: $n=6$ from 2 mice, -4.41 \pm 1.03. Mann-Whitney, $U=7, p=0.09$ ) were not different between wild-type and fmrl KO neurons. Our results suggest that the differences in $\mathrm{Na}^{+}$channel function do not contribute to the threshold and $\mathrm{dV} / \mathrm{dt}$ differences in dspikes between wildtype and fmr 1 KO CA1 pyramidal neurons.

\section{A-type $\mathrm{K}^{+}$channel block restores dspike threshold in fmr1 KO neurons}

A-type $\mathrm{K}^{+}$currents $\left(\mathrm{I}_{\mathrm{KA}}\right)$ are smaller in fmr1 KO CA1 neurons compared with wild type (Routh et al., 2013). We did not initially consider differences in $\mathrm{I}_{\mathrm{KA}}$ as a potential cause for the lack of TA-LTP in fmr1 KO neurons as we would expect the reduction in $\mathrm{I}_{\mathrm{KA}}$ to either promote or have no effect on dspikes. There is, however, a hyperpolarized shift in the activation of A-type $\mathrm{K}^{+}$ channels in fmr1 KO dendrites compared with wild type (Routh et al., 2013). A-type $\mathrm{K}^{+}$channels that activate at more negative potentials could overlap with $\mathrm{Na}^{+}$currents and influence dspikes in $f m r 1 \mathrm{KO}$ neurons. Furthermore, low concentrations of $\mathrm{Ba}^{2+}$ have been shown to affect transient $\mathrm{K}^{+}$currents expressed in the heart (Shi et al., 2000). We thus hypothesized that A-type $\mathrm{K}^{+}$ channels influence dspikes in $f m r 1 \mathrm{KO}$ but not wild-type CA1 neurons. As an initial test of this hypothesis, we recorded dspikes under control conditions, $25 \mu \mathrm{M} \mathrm{Ba}^{2+}$ (used in Fig. 7) and 150 $\mu \mathrm{M} \mathrm{Ba}{ }^{2+}$, a concentration known to block A-type $\mathrm{K}^{+}$channels (Gasparini et al., 2007; Routh et al., 2013; Fig. 11A-C). Neither concentration of $\mathrm{Ba}^{2+}$ had an effect on dspike threshold in wild-type neurons; however, dspike threshold was significantly hyperpolarized by 25 or $150 \mu \mathrm{M} \mathrm{Ba}^{2+}$ in $f m r 1 \mathrm{KO}$ neurons (Fig. $11 A-C$; wild type: $n=7$ from 3 mice; fmr 1 KO: $n=8$ from 2 mice; two-way RM ANOVA, $F_{(1,13)}=4.9, p=0.045, \eta^{2}=0.15$. Interaction, $F_{(2,26)}=11.51, p=0.0003, \eta^{2}=0.13$. Sidak's test baseline, $p=0.001, \eta^{2}=0.64$; wild type: $-36.14 \pm 1.09 \mathrm{mV}$; fmr1 KO: $-29.3 \pm 0.79 \mathrm{mV})$. These results support the hypothesis that A-type $\mathrm{K}^{+}$channels contribute to the depolarized dspike threshold in fmr1 KO CA1 neurons. These data also suggest that $\mathrm{Ba}^{2+}$ rescued TA-LTP in $f m r 1 \mathrm{KO}$ neurons by hyperpolarizing the threshold for dspike generation.

In $f m r 1 \mathrm{KO} C A 1$ pyramidal neurons, dendritic A-type $\mathrm{K}^{+}$ channels have a hyperpolarized activation curve and reduced maximal current amplitude (Routh et al., 2013). Are these apparent counteracting changes (easier to activate but reduced amplitude) in dendritic A-type $\mathrm{K}^{+}$channels sufficient to alter dspike initiation? To answer this question, we performed simulations using an established model of CA1 dendrites and dspike generation (Gasparini et al., 2004; accession \#44050, ModelDB). As in our current-clamp experiments, dendritic input was simulated by a single double exponential current injection sufficient to produce a dspike. Under control conditions the threshold for simulated dspikes was $-35.3 \mathrm{mV}$ (Fig. $11 D$, black), consistent with dspikes recorded from wild-type CA1 dendrites (-36.1 \pm $1.09 \mathrm{mV}$ ). To simulate the phenotype in $f m r 1 \mathrm{KO} C A 1$ dendrites, A-type $\mathrm{K}^{+}$channel $\mathrm{V}_{1 / 2}$ was hyperpolarized to $-10.9 \mathrm{mV}$ and $\mathrm{G}_{\text {density }}$ reduced to $0.0035 \mathrm{pS} / \mathrm{cm}^{2}$. Under these knock-out conditions the threshold for dspikes was $-29.4 \mathrm{mV}$ (Fig. $11 \mathrm{D}$, red), consistent with dspikes recorded from fmr1 KO CA1 dendrites $(-29.3 \pm 0.79 \mathrm{mV})$. These results indicate that the known alterations in dendritic A-type $\mathrm{K}^{+}$channel properties in fmr1 KO CA1 neurons can depolarize dspike threshold (Fig. 11E).

Although extracellular $\mathrm{Ba}^{2+}$ can be used to test for A-type $\mathrm{K}^{+}$ channels (Gasparini et al., 2007; Routh et al., 2013; Kalmbach et al., 2015), $\mathrm{Ba}^{2+}$ can also block inwardly rectifying $\mathrm{K}^{+}$channels (Fig. 7; Gasparini et al., 2004; Kim and Johnston, 2015; Ordemann et al., 2019). To explicitly test for the contribution of A-type $\mathrm{K}^{+}$channels to dendritic spike threshold, we used the Atype $\mathrm{K}^{+}$-channel-specific blocker AmmTx3 (500 nm; Chittajallu et al., 2020; Hu et al., 2020). In agreement with our $\mathrm{Ba}^{2+}$ experiments, AmmTx3 significantly reduced dspike threshold in fmr1 KO CA1 dendrites but had no effect on wild-type dspikes (Fig. $11 F, G$; wild type: $n=6$ from 3 mice; pre-AmmTx3: $-32.56 \pm$ $0.65 \mathrm{mV}$, post-AmmTx3: $-31.91 \pm 1.11 \mathrm{mV}$. Wilcoxon, $W=5$, $p=0.69$; fmr1 KO: $n=6$ from 3 mice; pre-AmmTx3: $-25.52 \pm$ $2.29 \mathrm{mV}$, post-AmmTx3: $-33.84 \pm 1.8 \mathrm{mV}$. Wilcoxon, $W=$ $\left.-21, p=0.03, \eta^{2}=0.65\right)$. 

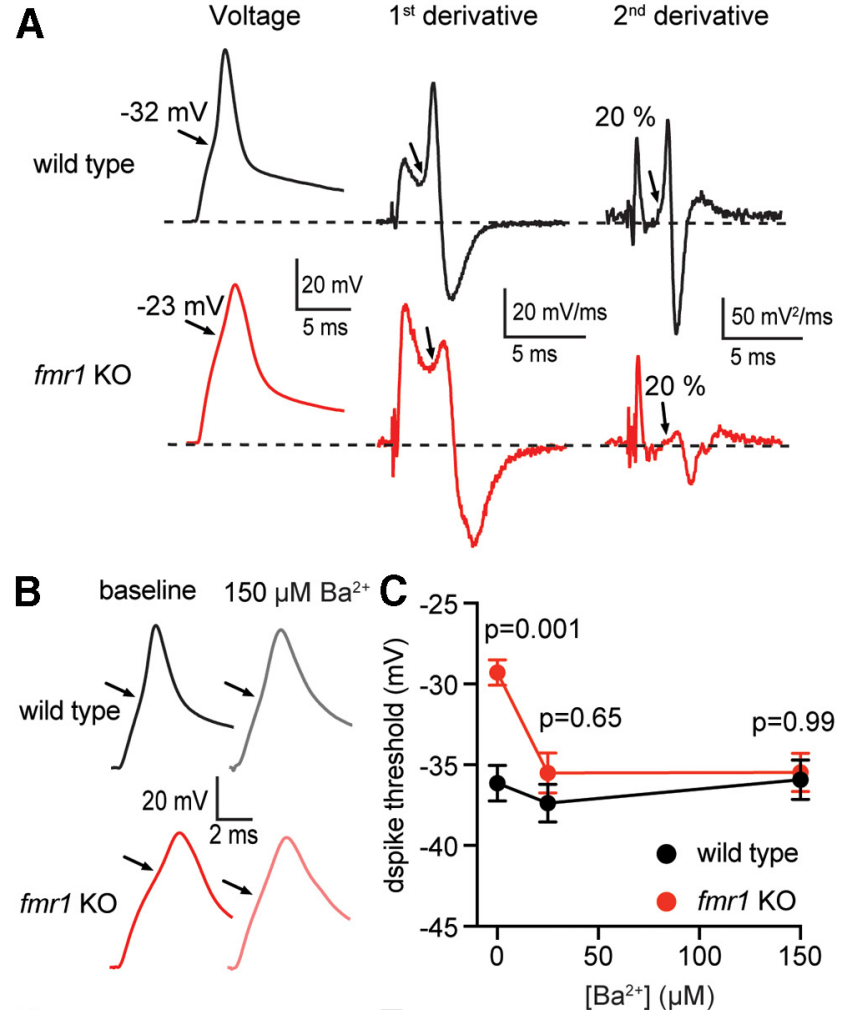

D
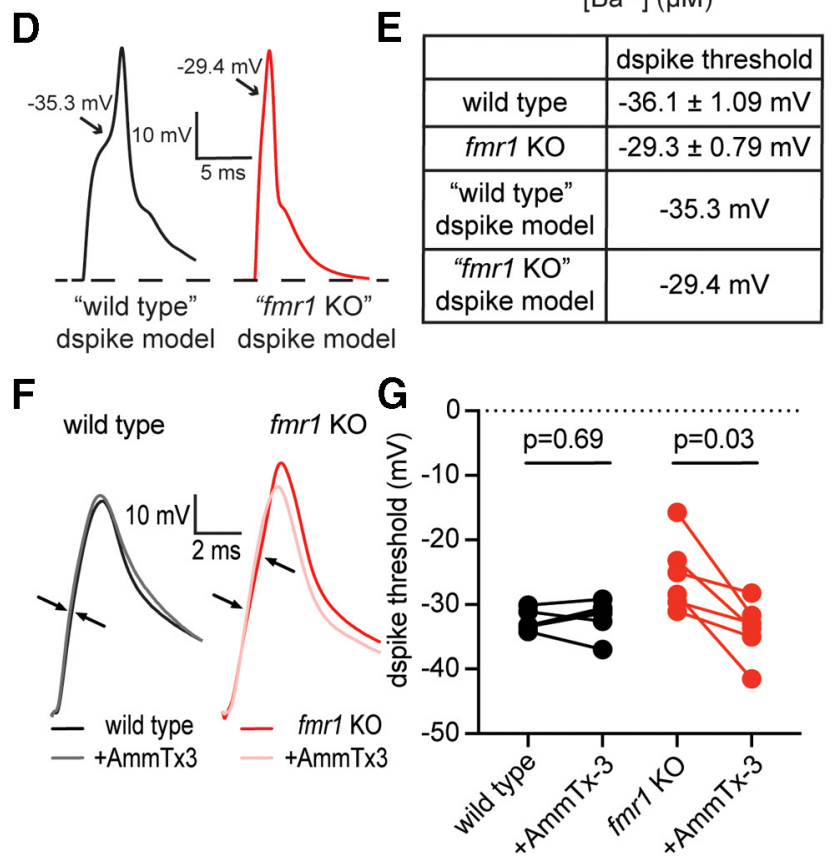

Figure 11. Block of A-type $\mathrm{K}^{+}$channels hyperpolarizes dspike threshold in fmr $1 \mathrm{KO}$ neurons. $A$, Representative dspike recordings showing recorded voltage (left), first derivative (middle), and second derivative (right). Threshold was determined as 20\% of the second peak of the second derivative (arrows). $\boldsymbol{B}$, Representative dspikes during baseline and application of $150 \mu \mathrm{m} \mathrm{Ba}{ }^{2+}$ in wild-type and fmr1 KO CA1 pyramidal neurons. C, Extracellular $\mathrm{Ba}^{2+}$ hyperpolarizes dspike threshold in $f m r 1 \mathrm{KO}$ but not wild-type dendrites (two-way RM ANOVA, $\left.F_{(1,13)}=4.9, p=0.045, \eta^{2}=0.15\right)$. Interaction, $F_{(2,26)}=11.51, p=0.0003, \eta^{2}=$ 0.13 . Sidak's test, $\left.0 \mu \mathrm{m} \mathrm{Ba}{ }^{2+}, p=0.001, \eta^{2}=0.64\right)$. D, Simulation of dspikes under control (black; $\mathrm{V}_{1 / 2}:-0.1, \mathrm{G}_{\text {density }}: 0.008 \mathrm{pS} / \mathrm{cm}^{2}$ ) and $f m r 1 \mathrm{KO}$ like A-type $\mathrm{K}^{+}$channel properties (red; $V_{1 / 2}:-0.1, G_{\text {density: }} 0.0035 \mathrm{pS} / \mathrm{cm}^{2}$ ). E, Dspike threshold from current-clamp recordings from wild-type and fmr $1 \mathrm{~K} 0$ dendrites $\left(0 \mu \mathrm{MBa}{ }^{2+}\right.$ condition from $\left.C\right)$ and simulations with normal and $f m r 1 \mathrm{KO}$-like A-type $\mathrm{K}^{+}$channel properties. $\boldsymbol{F}$, Representative dspike recordings from wild-type and fmr 1 K0 neurons before and after application of 500 nм AmmTx3. Arrows indicate threshold for dspike generation. G, AmmTx3 significantly hyperpolarized
A-type $\mathrm{K}^{+}$channel block restores TA-LTP in fmr1 KO neurons To test whether blocking of A-type $\mathrm{K}^{+}$channels rescued TALTP in fmrl KO neurons, we repeated the TBS TA-LTP experiments in the presence of the A-type $\mathrm{K}^{+}$channel blocker AmmTx3 (500 nM). Blockade of A-type $\mathrm{K}^{+}$channels with 500 nм AmmTx3 rescued TA-LTP in fmr1 KO CA1 pyramidal neurons (Fig. $12 A-C$; wild type: $n=6$ from 3 mice; pre-TBS: $0.13 \pm$ $0.017 \mathrm{mV} / \mathrm{ms}$, post-TBS: $0.23 \pm 0.032 \mathrm{mV} / \mathrm{ms}$. Wilcoxon, $W=$ 21, $p=0.03, \eta^{2}=0.79$. fmr 1 KO: $n=6$ from 3 mice; pre-TBS: $0.11 \pm 0.027 \mathrm{mV} / \mathrm{ms}$, post-TBS: $0.21 \pm 0.048 \mathrm{mV} / \mathrm{ms}$. Wilcoxon, $\left.W=21, p=0.03, \eta^{2}=0.79\right)$. The area under the curve during TBS was not different while AmmTx3 was present in the bath (Fig. $12 D$,E; wild type: $22.62 \pm 3.51 \mathrm{mV}^{\star} \mathrm{ms}$; fmr1 KO: $22.58 \pm$ $4.65 \mathrm{mV}^{\star} \mathrm{ms}$. Mann-Whitney, $U=16, p=0.82$ ). Together, these results suggest that the hyperpolarized shift in activation of Atype $\mathrm{K}^{+}$channels in fmrl KO CA1 pyramidal neuron dendrites results in a depolarized threshold for dspikes and a lack of TALTP.

\section{Discussion}

TBS induces behaviorally relevant LTP of TA inputs in wild-type CA1 neurons, which is critical to hippocampal-dependent learning and memory (Remondes and Schuman, 2004; Bittner et al., 2017). We found that TBS fails to induce TA-LTP in fmrl KO CA1 pyramidal neurons. We previously identified an increase in the expression of dendritic h-channels in fmrl KO CA1 dendrites (Brager et al., 2012; Brandalise et al., 2020). We thus hypothesized that decreased summation of TA inputs would account for impairments in TA-LTP. However, blocking h-channels with ZD7288 did not rescue TA-LTP in fmr1 KO neurons. We cannot rule out the contribution of h-channelopathy to reduced synaptic summation leading to impaired TA-LTP. TALTP requires $\mathrm{Ca}^{2+}$ influx through NMDARs and L-type voltagegated $\mathrm{Ca}^{2+}$ channels (Golding et al., 2002; Remondes and Schuman, 2003). Two-photon $\mathrm{Ca}^{2+}$ imaging demonstrated that synaptically evoked dendritic $\mathrm{Ca}^{2+}$ signals were smaller in $\mathrm{fmrl}$ $\mathrm{KO}$ neurons. We found that basal TA synaptic transmission was not different between wild-type and fmr1 KO mice as was described previously (Wahlstrom-Helgren and Klyachko, 2015) but see (Booker et al., 2020). Interestingly, we found no difference in NMDAR EPSPs, dendritic complex spikes, or isolated dendritic $\mathrm{Ca}^{2+}$ spikes between wild-type and fmr1 KO CA1 pyramidal neurons. Dendritic $\mathrm{Na}^{+}$-mediated spikes are necessary and trigger the influx of $\mathrm{Ca}^{2+}$ necessary for TA-LTP (Golding et al., 2002; Kim et al., 2015). We found that dspike threshold is depolarized in fmrl $\mathrm{KO}$ dendrites and suggest that an inability of TA TBS to trigger dspikes likely contributes to TA-LTP dysfunction. Indeed, depolarization of the dendritic membrane potential in $f m r 1 \mathrm{KO}$ neurons through blockade of $\mathrm{K}_{\mathrm{IR}}$ channels or direct dendritic current injection restored TA-LTP. Our lab previously demonstrated that A-type $\mathrm{K}^{+}$channel expression is reduced in the dendrites of fmr 1 KO CA1 pyramidal neurons, and the activation is shifted to more hyperpolarized potentials (Routh et al., 2013). Despite a reduction in A-type $\mathrm{K}^{+}$channel expression, the hyperpolarized shift in activation resulted in a depolarized dspike threshold in fmr $1 \mathrm{KO}$ CA1 dendrites and the rescue of TA-LTP and dspike threshold in fmrl KO neurons by the addition of the A-type $\mathrm{K}^{+}$channel blocker AmmTx3.

$\leftarrow$

dspike threshold in fmr1 K0 but not wild-type CA1 neurons (wild type: Wilcoxon, $W=5$, $p=0.69$; fmr1 K0: Wilcoxon, $W=-21, p=0.03, \eta^{2}=0.65$ ). 

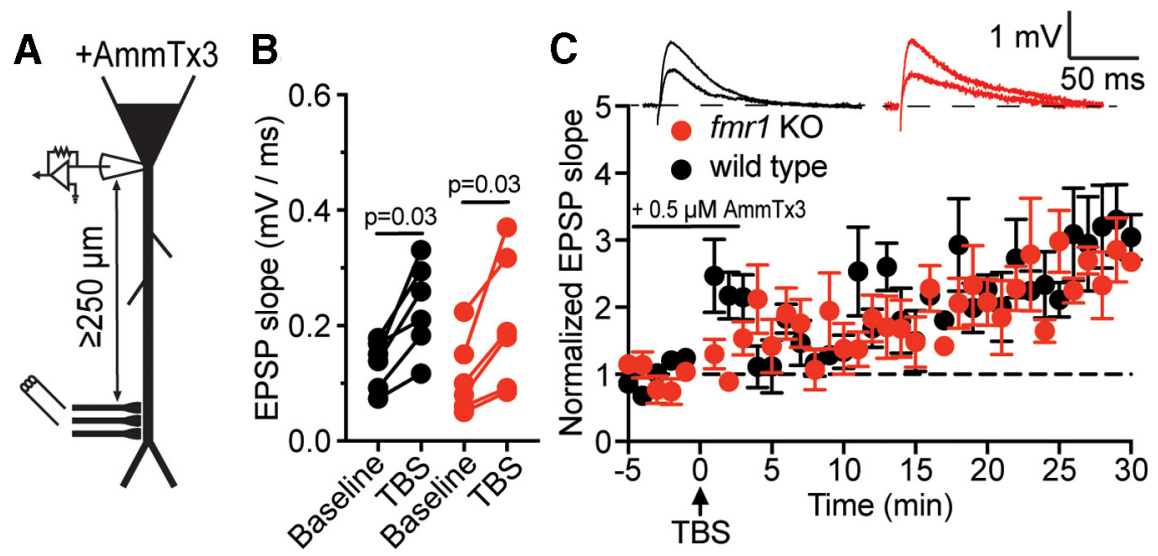

D

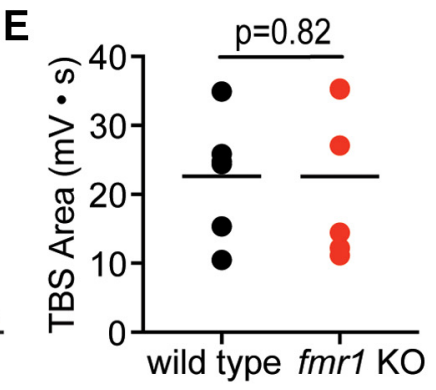

Figure 12. Block of A-type $\mathrm{K}^{+}$channels restores TA-LTP in fmr1 K0 neurons. A, Recording configuration for AmmTx3 TALTP experiments. $\boldsymbol{B}$, EPSP slope is significantly increased $30 \mathrm{~min}$ after TBS in both wild-type and fmr $1 \mathrm{KO}$ CA1 neurons (wild type: Wilcoxon, $W=21, p=0.03, \eta^{2}=0.79 ;$ fmr1 K0: Wilcoxon, $\left.W=21, p=0.03, \eta^{2}=0.79\right)$. C, Normalized EPSP slope $5 \mathrm{~min}$ before and $30 \mathrm{~min}$ after TBS of TA inputs. Inset, Representative baseline and post-TBS EPSPs from wild-type and fmr $1 \mathrm{KO}$ CA1 neurons. $\boldsymbol{D}$, Representative traces showing the somatic response during TBS. $\boldsymbol{E}$, Group data of area under the curve during TBS (Mann-Whitney, $U=16, p=0.82$ ).

\section{Dendritic nonlinear events in fmr1 KO CA1 neurons}

We provide the first direct comparison of dendritic nonlinear events (complex spikes, $\mathrm{Ca}^{2+}$ spikes, and dendritic $\mathrm{Na}^{+}$spikes) between wild-type and fmrl KO CA1 neurons. Fast $\mathrm{Na}^{+}$-dependent dspikes are essential for the induction TA-LTP (Kim et al., 2015). We found that the threshold was more depolarized, and the maximum $\mathrm{dV} / \mathrm{dt}$ was slower for dspikes in $\mathrm{fmr} 1 \mathrm{KO}$ dendrites compared with wild-type. Dendritic complex spikes, which are the combined effect of dendritic $\mathrm{Na}^{+}$and $\mathrm{Ca}^{2+}$ channels, were not different in frequency or width between wild-type and fmr1 KO CA1 pyramidal neurons. Recordings of isolated dendritic $\mathrm{Ca}^{2+}$ spikes suggest that CA1 dendritic voltage-gated $\mathrm{Ca}^{2+}$ channels are not different between wild-type and fmr1 KO neurons. Previous studies have shown that changes in voltage-gated $\mathrm{Ca}^{2+}$ channels in fmrl KO mice occur in a brain region and celltype-specific manner (Meredith et al., 2007; Danesi et al., 2018; Gray et al., 2019). Our results further illustrate that changes in ion channel function and expression in FXS are not conserved across brain regions.

\section{A-type $\mathrm{K}^{+}$channels contribute to dspikes in fmr1 KO but not wild-type CA1 neurons}

The threshold for regenerative events is determined by the complement of ion channels and their relative kinetics (Hodgkin and Huxley, 1952a, b; Stafstrom et al., 1984). In particular, there is an interplay between depolarizing sodium conductances and hyperpolarizing potassium conductances. We provide the first investigation of dendritic voltage-gated $\mathrm{Na}^{+}$channels in CA1 dendrites of $f m r 1 \mathrm{KO}$ mice. The properties of voltage-gated $\mathrm{Na}^{+}$currents in our wild-type mouse dendritic recordings were comparable to previous findings in rats (Magee and Johnston, 1995; Gasparini and Magee, 2002) and were not different between wild-type and fmrl KO CA1 pyramidal neurons.

The activation of A-type $\mathrm{K}^{+}$channels is hyperpolarized in fmrl KO CA1 neuron dendrites (Routh et al., 2013). We hypothesize that the hyperpolarized shift in $\mathrm{I}_{\mathrm{KA}}$ activation in fmrl $\mathrm{KO}$ dendrites allows A-type $\mathrm{K}^{+}$channels to provide more opposition to $\mathrm{Na}^{+}$-dependent depolarization and depolarizes dspike threshold. Similar modulation of action potential threshold is known to occur via somatic D-type $\mathrm{K}^{+}$channels (Higgs and Spain, 2011; Kalmbach et al., 2015; Ordemann et al., 2019).

Our results support this hypothesis, showing that direct depolarization of dendrites during TBS was sufficient to rescue TA-LTP in fmrl KO CA1 neurons. Furthermore, both 25 and $150 \mu \mathrm{M}$ extracellular $\mathrm{Ba}^{2+}$ hyperpolarized dspike threshold in fmr1 KO but had no effect in wildtype CA1 neurons. Simulations of CA1 dspikes, in which A-type $\mathrm{K}^{+}$channel function was modified to be consistent with the fmrl KO phenotype, recapitulated the difference between wild-type and $f m r 1 \mathrm{KO}$ dspikes. Finally, we confirmed that blockade of $\mathrm{I}_{\mathrm{KA}}$ hyperpolarized dspike threshold and rescued TALTP with the specific A-type $\mathrm{K}^{+}$channel blocker AmmTx3.

\section{Potential mechanism for the hyperpolarized activation of $A$ - type $\mathrm{K}^{+}$channels}

The voltage dependence of A-type $\mathrm{K}^{+}$channels in CA1 pyramidal dendrites is modulated by multiple signaling cascades. Stimulation of protein kinase C (PKC), by activation of metabotropic glutamate and muscarinic acetylcholine receptors, and cAMP-dependent protein kinase A (PKA), by dopaminergic and $\beta$-adrenergic receptors, produce a depolarizing shift in the of activation of A-type $\mathrm{K}^{+}$channels (Hoffman and Johnston, 1998, 1999).

Reduction in PKC and/or PKA activity could account for the hyperpolarization of A-type $\mathrm{K}^{+}$channel activation in $\mathrm{fmrl} \mathrm{KO}$ CA1 neurons. There is evidence from human and animal models of FXS exhibiting lower cAMP levels (Berry-Kravis and Huttenlocher, 1992; Choi et al., 2015). Lower cAMP levels could reduce basal PKA activity and lead to a hyperpolarized shift of A-type $\mathrm{K}^{+}$channel activation. A study on cortical synaptoneurosomes found that basal PKC activity was not different between wild-type and fmr1 KO mice (Weiler et al., 2004). A more recent study, however, found that PKC $\varepsilon$ expression was lower in the hippocampus of fmr1 KO mice (Marsillo et al., 2021). PKC $\varepsilon$ is abundant in the nervous system and activated by $G$ proteincoupled receptors (Akita, 2002). Furthermore, PKC $\varepsilon$ is activated by phorbol esters, which were used to investigate $\mathrm{PKC}$-dependent modulation of A-type $\mathrm{K}^{+}$channels (Hoffman and Johnston, 1998). Thus, $\mathrm{PKC} \varepsilon$ is a potential candidate for regulating the voltage dependence of A-type $\mathrm{K}^{+}$channel activation. Additionally, FMRP is a positive regulator of both PKA (Sears et al., 2019) and 
PKC (Zhao et al., 2015); therefore, loss of FMRP in FXS could result in reduced PKA and PKC activity. Thus, changes in the basal activity of PKA and/or PKC could contribute to the hyperpolarized shift in A-type $\mathrm{K}^{+}$channel activation that alters dspike threshold and impairs TA-LTP in fmr1 KO CA1 neurons.

\section{Consequences for hippocampal learning and memory}

There are two major changes in A-type $\mathrm{K}^{+}$channel function in $f m r 1 \mathrm{KO}$ CA1 dendrites-lower maximum current and hyperpolarized activation. LTP induction of excitatory inputs to CA1 pyramidal neurons requires active dendritic events. Schaffer collateral LTP requires backpropagating action potentials to provide the depolarization necessary for NMDA receptor activation (Magee and Johnston, 1997). In the SLM region of CA1 however, where the TA inputs synapse onto the distal dendrites of CA1 pyramidal neurons, backpropagating action potentials are unreliable and often fail to propagate into the distal apical dendrites. Rather, it is locally generated dspikes that provide the necessary depolarizing signal for the induction of LTP. Alterations in dendritic A-type $\mathrm{K}^{+}$channel function in fmr1 KO CA1 pyramidal neurons causes changes to the active events affecting LTP of both excitatory pathways. Reduced maximal A-type $\mathrm{K}^{+}$current allows the amplitude of back propagating action potentials to be larger, which results in a reduced threshold for Schaffer collateral LTP (Routh et al., 2013). By contrast, the hyperpolarized shift in the activation of A-type $\mathrm{K}^{+}$channels provides a small, but effective, hyperpolarizing influence on the dendritic membrane potential that depolarizes dspike threshold and impairs TA-LTP. The coordinated plasticity of TA inputs, which convey current information about the external environment, and Schaffer collateral inputs, which convey stored information from prior experiences, is critical for hippocampal-dependent memory tasks. The combined changes in A-type $\mathrm{K}^{+}$channel function alter the dendritic processing of these two critical excitatory pathways. Our findings show an inability to induce LTP in TA synapses in a pathway critical for the induction of long-term memory (Remondes and Schuman, 2004). This finding provides critical new information for the understanding of the FXS disease phenotype.

FXS is marked by deficits in learning and memory, making the discovery of specific therapeutic targets necessary for the understanding and future treatment of the disorder. Our previous work, along with other studies, showed how changes in the expression of A-type $\mathrm{K}^{+}$channels affect Schaffer collateral LTP in FXS (Gross et al., 2011; Lee et al., 2011; Routh et al., 2013). Here, we show that changes in the properties of A-type $\mathrm{K}^{+}$channels have an impact on TA-LTP. Therefore, although A-type $\mathrm{K}^{+}$ channels represent a potential therapeutic target for FXS interventions, manipulations must take into account both the change in expression and the shift in gating.

\section{References}

Akita Y (2002) Protein kinase C-epsilon (PKC-epsilon): its unique structure and function. J Biochem 132:847-852.

Andreasen M, Lambert JD (1995) Regenerative properties of pyramidal cell dendrites in area CA1 of the rat hippocampus. J Physiol 483: 421-441.

Bassell GJ, Warren ST (2008) Fragile X syndrome: loss of local mRNA regulation alters synaptic development and function. Neuron 60:201-214.

Benardo LS, Masukawa LM, Prince DA (1982) Electrophysiology of isolated hippocampal pyramidal dendrites. J Neurosci 2:1614-1622.
Berry-Kravis E, Huttenlocher PR (1992) Cyclic AMP metabolism in Fragile $\mathrm{X}$ syndrome. Ann Neurol 31:22-26.

Bittner KC, Milstein AD, Grienberger C, Romani S, Magee JC (2017) Behavioral time scale synaptic plasticity underlies CA1 place fields. Science 357:1033-1036.

Booker SA, Simões de Oliveira L, Anstey NJ, Kozic Z, Dando OR, Jackson AD, Baxter PS, Isom LL, Sherman DL, Hardingham GE, Brophy PJ, Wyllie DJA, Kind PC (2020) Input-output relationship of CA1 pyramidal neurons reveals intact homeostatic mechanisms in a mouse model of Fragile X syndrome. Cell Rep 32:107988.

Bostrom CA, Majaess N-M, Morch K, White E, Eadie BD, Christie BR (2015) Rescue of NMDAR-dependent synaptic plasticity in Fmr1 knock-out mice. Cereb Cortex 25:271-279.

Brager DH, Akhavan AR, Johnston D (2012) Impaired dendritic expression and plasticity of h-channels in the fmrl(-/y) mouse model of Fragile $\mathrm{X}$ syndrome. Cell Rep 1:225-233.

Brandalise F, Kalmbach BE, Mehta P, Thornton O, Johnston D, Zemelman BV, Brager DH (2020) Fragile X mental retardation protein bidirectionally controls dendritic ih in a cell type-specific manner between mouse hippocampus and prefrontal cortex. J Neurosci 40:5327-5340.

Brown MR, Kronengold J, Gazula V-R, Chen Y, Strumbos JG, Sigworth FJ, Navaratnam D, Kaczmarek LK (2010) Fragile X mental retardation protein controls gating of the sodium-activated potassium channel Slack. Nat Neurosci 13:819-821.

Brown WT, Jenkins EC, Friedman E, Brooks J, Wisniewski K, Raguthu S, French J (1982) Autism is associated with the Fragile-X syndrome. J Autism Dev Disord 12:303-308.

Carnevale NT, Hines ML (2009) The NEURON book. Cambridge, UK: Cambridge University Press.

Chen X, Johnston D (2004) Properties of single voltage-dependent K+ channels in dendrites of CA1 pyramidal neurones of rat hippocampus. J Physiol 559:187-203.

Chittajallu R, Auville K, Mahadevan V, Lai M, Hunt S, Calvigioni D, Pelkey KA, Zaghloul KA, McBain CJ (2020) Activity-dependent tuning of intrinsic excitability in mouse and human neurogliaform cells. Elife 9:57571.

Choi CH, Schoenfeld BP, Weisz ED, Bell AJ, Chambers DB, Hinchey J, Choi RJ, Hinchey P, Kollaros M, Gertner MJ, Ferrick NJ, Terlizzi AM, Yohn N, Koenigsberg E, Liebelt DA, Zukin RS, Woo NH, Tranfaglia MR, Louneva N, Arnold SE, et al. (2015) PDE-4 inhibition rescues aberrant synaptic plasticity in Drosophila and mouse models of Fragile X syndrome. J Neurosci 35:396-408.

Cohen J (1988) Statistical power analysis for the behavioral sciences. Hillsdale, NJ: Erlbaum.

Danesi C, Achuta VS, Corcoran P, Peteri U-K, Turconi G, Matsui N, Albayrak I, Rezov V, Isaksson A, Castrén ML (2018) Increased calcium influx through L-type calcium channels in human and mouse neural progenitors lacking Fragile X mental retardation protein. Stem Cell Reports 11:1449-1461.

Darnell JC, Van Driesche SJ, Zhang C, Hung KYS, Mele A, Fraser CE, Stone EF, Chen C, Fak JJ, Chi SW, Licatalosi DD, Richter JD, Darnell RB (2011) FMRP stalls ribosomal translocation on mRNAs linked to synaptic function and autism. Cell 146:247-261.

Deng P-Y, Rotman Z, Blundon JA, Cho Y, Cui J, Cavalli V, Zakharenko SS, Klyachko VA (2013) FMRP regulates neurotransmitter release and synaptic information transmission by modulating action potential duration via BK channels. Neuron 77:696-711.

Deng P-Y, Carlin D, Oh YM, Myrick LK, Warren ST, Cavalli V, Klyachko VA (2019) Voltage-independent SK-channel dysfunction causes neuronal hyperexcitability in the hippocampus of Fmr1 knock-out mice. J Neurosci 39:28-43.

Gasparini S, Magee JC (2002) Phosphorylation-dependent differences in the activation properties of distal and proximal dendritic $\mathrm{Na}+$ channels in rat CA1 hippocampal neurons. J Physiol 541:665-672.

Gasparini S, Migliore M, Magee JC (2004) On the initiation and propagation of dendritic spikes in CA1 pyramidal neurons. J Neurosci 24:1104611056.

Gasparini S, Losonczy A, Chen X, Johnston D, Magee JC (2007) Associative pairing enhances action potential back-propagation in radial oblique branches of CA1 pyramidal neurons. J Physiol 580:787-800.

Golding NL, Spruston N (1998) Dendritic sodium spikes are variable triggers of axonal action potentials in hippocampal CA1 pyramidal neurons. Neuron 21:1189-1200. 
Golding NL, Jung HY, Mickus T, Spruston N (1999) Dendritic calcium spike initiation and repolarization are controlled by distinct potassium channel subtypes in CA1 pyramidal neurons. J Neurosci 19:8789-8798.

Golding NL, Staff NP, Spruston N (2002) Dendritic spikes as a mechanism for cooperative long-term potentiation. Nature 418:326-331.

Golding NL, Mickus TJ, Katz Y, Kath WL, Spruston N (2005) Factors mediating powerful voltage attenuation along CA1 pyramidal neuron dendrites. J Physiol 568:69-82.

Gray EE, Murphy JG, Liu Y, Trang I, Tabor GT, Lin L, Hoffman DA (2019) Disruption of GpI mGluR-dependent Cav2.3 translation in a mouse model of Fragile X syndrome. J Neurosci 39:7453-7464.

Gross C, Yao X, Pong DL, Jeromin A, Bassell GJ (2011) Fragile X mental retardation protein regulates protein expression and mRNA translation of the potassium channel Kv4.2. J Neurosci 31:5693-5698.

Higgs MH, Spain WJ (2011) Kvl channels control spike threshold dynamics and spike timing in cortical pyramidal neurones. J Physiol 589:51255142.

Hodgkin AL, Huxley AF (1952a) A quantitative description of membrane current and its application to conduction and excitation in nerve. J Physiol 117:500-544.

Hodgkin AL, Huxley AF (1952b) Currents carried by sodium and potassium ions through the membrane of the giant axon of Loligo. J Physiol 116:449-472.

Hoffman DA, Johnston D (1998) Downregulation of transient K+ channels in dendrites of hippocampal CA1 pyramidal neurons by activation of PKA and PKC. J Neurosci 18:3521-3528.

Hoffman DA, Johnston D (1999) Neuromodulation of dendritic action potentials. J Neurophysiol 81:408-411.

Hoffman DA, Magee JC, Colbert CM, Johnston D (1997) K+ channel regulation of signal propagation in dendrites of hippocampal pyramidal neurons. Nature 387:869-875.

Hu J-H, Malloy C, Tabor GT, Gutzmann JJ, Liu Y, Abebe D, Karlsson R-M, Durell S, Cameron HA, Hoffman DA (2020) Activity-dependent isomerization of Kv4.2 by Pin1 regulates cognitive flexibility. Nat Commun 11:1567.

Huber KM, Gallagher SM, Warren ST, Bear MF (2002) Altered synaptic plasticity in a mouse model of Fragile X mental retardation. Proc Natl Acad Sci U S A 99:7746-7750.

Kalmbach BE, Johnston D, Brager DH (2015) Cell-type specific channelopathies in the prefrontal cortex of the fmr1-/y mouse model of Fragile X syndrome. eNeuro 2:ENEURO.0114-15.2015.

Kemper MB, Hagerman RJ, Altshul-Stark D (1988) Cognitive profiles of boys with the Fragile X syndrome. Am J Med Genet 30:191-200.

Kim CS, Johnston D (2015) A1 adenosine receptor-mediated GIRK channels contribute to the resting conductance of CA1 neurons in the dorsal hippocampus. J Neurophysiol 113:2511-2523.

Kim Y, Hsu C-L, Cembrowski MS, Mensh BD, Spruston N (2015) Dendritic sodium spikes are required for long-term potentiation at distal synapses on hippocampal pyramidal neurons. Elife 4:e06414.

Lee HY, Ge W-P, Huang W, He Y, Wang GX, Rowson-Baldwin A, Smith SJ, Jan YN, Jan LY (2011) Bidirectional regulation of dendritic voltage-gated potassium channels by the Fragile $\mathrm{X}$ mental retardation protein. Neuron 72:630-642.

Lubs HA (1969) A marker X chromosome. Am J Hum Genet 21:231-244.

Ludwig AL, Espinal GM, Pretto DI, Jamal AL, Arque G, Tassone F, Berman RF, Hagerman PJ (2014) CNS expression of murine Fragile X protein (FMRP) as a function of CGG-repeat size. Hum Mol Genet 23:32283238.

Magee JC (1998) Dendritic hyperpolarization-activated currents modify the integrative properties of hippocampal CA1 pyramidal neurons. J Neurosci 18:7613-7624.

Magee J (1999) Dendritic Ih normalizes temporal summation in hippocampal CA1 neurons. Nat Neurosci 2:848-848.

Magee JC, Johnston D (1995) Characterization of single voltage-gated $\mathrm{Na}+$ and $\mathrm{Ca} 2+$ channels in apical dendrites of rat CA1 pyramidal neurons. J Physiol 487:67-90.

Magee JC, Johnston D (1997) A synaptically controlled, associative signal for Hebbian plasticity in hippocampal neurons. Science 275:209-213.
Malik R, Johnston D (2017) Dendritic GIRK channels gate the integration window, plateau potentials, and induction of synaptic plasticity in dorsal but not ventral CA1 neurons. J Neurosci 37:3940-3955.

Marsillo A, David L, Gerges B, Kerr D, Lasiychuk V, Sadek R, Salame D, Soliman Y, Menkes S, Chatterjee A, Mancuso A, Banerjee P (2021) PKC epsilon as a neonatal target to correct FXS-linked AMPA receptor translocation in the hippocampus, boost PVN oxytocin expression, and normalize adult behavior in Fmr1 knockout mice. Biochim Biophys Acta Mol Basis Dis 1867:166048.

Martin JP, Bell J (1943) A pedigree of mental defect showing sex-linkage. J Neurol Psychiatry 6:154-157.

McDougal RA, Morse TM, Carnevale T, Marenco L, Wang R, Migliore M, Miller PL, Shepherd GM, Hines ML (2017) Twenty years of ModelDB and beyond: building essential modeling tools for the future of neuroscience. J Comput Neurosci 42:1-10.

Meredith RM, Holmgren CD, Weidum M, Burnashev N, Mansvelder HD (2007) Increased threshold for spike-timing-dependent plasticity is caused by unreliable calcium signaling in mice lacking Fragile $\mathrm{X}$ gene FMR1. Neuron 54:627-638.

Ordemann GJ, Apgar CJ, Brager DH (2019) D-type potassium channels normalize action potential firing between dorsal and ventral CA1 neurons of the mouse hippocampus. J Neurophysiol 121:983-995.

Ramos A, Hollingworth D, Adinolfi S, Castets M, Kelly G, Frenkiel TA, Bardoni B, Pastore A (2006) The structure of the N-terminal domain of the Fragile $\mathrm{X}$ mental retardation protein: a platform for protein-protein interaction. Structure 14:21-31.

Remondes M, Schuman EM (2003) Molecular mechanisms contributing to long-lasting synaptic plasticity at the temporoammonic-CA1 synapse. Learn Mem 10:247-252.

Remondes M, Schuman EM (2004) Role for a cortical input to hippocampal area CA1 in the consolidation of a long-term memory. Nature 431:699_ 703.

Rogers SJ, Wehner DE, Hagerman R (2001) The behavioral phenotype in Fragile X: symptoms of autism in very young children with Fragile X syndrome, idiopathic autism, and other developmental disorders. J Dev Behav Pediatr 22:409-417.

Routh BN, Johnston D, Brager DH (2013) Loss of functional A-type potassium channels in the dendrites of CA1 pyramidal neurons from a mouse model of Fragile X syndrome. J Neurosci 33:1944219450.

Schneider CA, Rasband WS, Eliceiri KW (2012) NIH Image to ImageJ: 25 years of image analysis. Nat Methods 9:671-675.

Scoville WB, Milner B (1957) Loss of recent memory after bilateral hippocampal lesions. J Neurol Neurosurg Psychiatry 20:11-21.

Sears JC, Choi WJ, Broadie K (2019) Fragile X mental retardation protein positively regulates PKA anchor Rugose and PKA activity to control actin assembly in learning/memory circuitry. Neurobiol Dis 127:53-64.

Shang Y, Wang H, Mercaldo V, Li X, Chen T, Zhuo M (2009) Fragile X mental retardation protein is required for chemically-induced long-term potentiation of the hippocampus in adult mice. J Neurochem 111:635646.

Shi H, Wang H-Z, Wang Z (2000) Extracellular Ba(2+) blocks the cardiac transient outward $\mathrm{K}(+)$ current. Am J Physiol Heart Circ Physiol 278: H295-H299.

Squire LR (1992) Memory and the hippocampus: a synthesis from findings with rats, monkeys, and humans. Psychol Rev 99:195-231

Stafstrom CE, Schwindt PC, Crill WE (1984) Repetitive firing in layer $\mathrm{V}$ neurons from cat neocortex in vitro. J Neurophysiol 52:264277.

Takahashi H, Magee JC (2009) Pathway interactions and synaptic plasticity in the dendritic tuft regions of CA1 pyramidal neurons. Neuron 62:102111.

Tassone F, Hagerman RJ, Loesch DZ, Lachiewicz A, Taylor AK, Hagerman PJ (2000) Fragile X males with unmethylated, full mutation trinucleotide repeat expansions have elevated levels of FMR1 messenger RNA. Am J Med Genet 94:232-236.

Toft AKH, Lundbye CJ, Banke TG (2016) Dysregulated NMDA-receptor signaling inhibits long-term depression in a mouse model of Fragile X syndrome. J Neurosci 36:9817-9827. 
Tsay D, Dudman JT, Siegelbaum SA (2007) HCN1 channels constrain synaptically evoked $\mathrm{Ca} 2+$ spikes in distal dendrites of CA1 pyramidal neurons. Neuron 56:1076-1089.

Turner G, Webb T, Wake S, Robinson H (1996) Prevalence of Fragile X syndrome. Am J Med Genet 64:196-197.

Verkerk AJ, Pieretti M, Sutcliffe JS, Fu YH, Kuhl DP, Pizzuti A, Reiner O, Richards S, Victoria MF, Zhang FP (1991) Identification of a gene (FMR1) containing a CGG repeat coincident with a breakpoint cluster region exhibiting length variation in Fragile $\mathrm{X}$ syndrome. Cell 65:905-914.

Wahlstrom-Helgren S, Klyachko VA (2015) GABAB receptor-mediated feed-forward circuit dysfunction in the mouse model of Fragile X syndrome. J Physiol 593:5009-5024.
Wang H, Ardiles AO, Yang S, Tran T, Posada-Duque R, Valdivia G, Baek M, Chuang Y-A, Palacios AG, Gallagher M, Worley P, Kirkwood A (2016) Metabotropic glutamate receptors induce a form of LTP controlled by translation and arc signaling in the hippocampus. J Neurosci 36:1723-1729.

Weiler IJ, Spangler CC, Klintsova AY, Grossman AW, Kim SH, Bertaina-Anglade V, Khaliq H, de Vries FE, Lambers FAE, Hatia F, Base CK, Greenough WT (2004) Fragile X mental retardation protein is necessary for neurotransmitter-activated protein translation at synapses. Proc Natl Acad Sci U S A 101:17504-17509.

Zhao W, Wang J, Song S, Li F, Yuan F (2015) Reduction of $\alpha 1$ GABAA receptor mediated by tyrosine kinase $\mathrm{C}(\mathrm{PKC})$ phosphorylation in a mouse model of Fragile X syndrome. Int J Clin Exp Med 8:1321913226. 